\title{
Modeling and evaluation of the global sea-salt aerosol distribution: sensitivity to emission schemes and resolution effects at coastal/orographic sites
}

\author{
M. Spada ${ }^{1}$, O. Jorba ${ }^{1}$, C. Pérez García-Pando ${ }^{2,3}$, Z. Janjic ${ }^{4}$, and J. M. Baldasano ${ }^{1,5}$ \\ ${ }^{1}$ Barcelona Supercomputing Center - Centro Nacional de Supercomputación, Barcelona, Spain \\ ${ }^{2}$ NASA Goddard Institute for Space Studies, New York, USA \\ ${ }^{3}$ Department of Applied Physics and Applied Math, Columbia University, New York, USA \\ ${ }^{4}$ National Centers for Environmental Prediction, College Park, Maryland, USA \\ ${ }^{5}$ Universitat Politècnica de Catalunya, Barcelona, Spain \\ Correspondence to: M. Spada (michele.spada@bsc.es) and O. Jorba (oriol.jorba@bsc.es)
}

Received: 21 March 2013 - Published in Atmos. Chem. Phys. Discuss.: 2 May 2013

Revised: 9 October 2013 - Accepted: 2 November 2013 - Published: 4 December 2013

\begin{abstract}
One of the major sources of uncertainty in model estimates of the global sea-salt aerosol distribution is the emission parameterization. We evaluate a new sea-salt aerosol life cycle module coupled to the online multiscale chemical transport model NMMB/BSC-CTM. We compare $5 \mathrm{yr}$ global simulations using five state-of-the-art sea-salt open-ocean emission schemes with monthly averaged coarse aerosol optical depth (AOD) from selected AERONET sun photometers, surface concentration measurements from the University of Miami's Ocean Aerosol Network, and measurements from two NOAA/PMEL cruises (AEROINDOEX and ACE1). Model results are highly sensitive to the introduction of sea-surface-temperature (SST)-dependent emissions and to the accounting of spume particles production. Emission ranges from $3888 \mathrm{Tg} \mathrm{yr}^{-1}$ to $8114 \mathrm{Tg} \mathrm{yr}^{-1}$, lifetime varies between $7.3 \mathrm{~h}$ and $11.3 \mathrm{~h}$, and the average column mass load is between 5.0 Tg and 7.2 Tg. Coarse AOD is reproduced with an overall correlation of around 0.5 and with normalized biases ranging from $+8.8 \%$ to $+38.8 \%$. Surface concentration is simulated with normalized biases ranging from $-9.5 \%$ to $+28 \%$ and the overall correlation is around 0.5 . Our results indicate that SST-dependent emission schemes improve the overall model performance in reproducing surface concentrations. On the other hand, they lead to an overestimation of the coarse AOD at tropical latitudes, although it may be affected by uncertainties in the comparison due to the use of all-sky model AOD, the treatment of
\end{abstract}

water uptake, deposition and optical properties in the model and/or an inaccurate size distribution at emission.

\section{Introduction}

Sea salt is one of the most abundant aerosol species globally. It perturbs the radiative fluxes directly by interacting with shortwave and longwave radiation, and indirectly by acting as cloud condensation nuclei (CCN) and thus altering marine cloud brightness and lifetime. It also influences heterogeneous chemistry mainly over coastal areas (Lewis and Schwartz, 2004) and is co-emitted with organic aerosols (Tsigaridis et al., 2013). The major uncertainties in the seasalt life cycle are emission (Textor et al., 2006; de Leeuw et al., 2011), water uptake (Textor et al., 2006), and deposition (Textor et al., 2007). Lewis and Schwartz (2004) estimate the total sea-salt emission to vary from $0.3 \mathrm{Tg} \mathrm{gr}^{-1}$ to $30 \mathrm{Tg} \mathrm{yr}^{-1}$ and estimates from models involved in the AEROCOM project range from $3 \mathrm{Tg} \mathrm{yr}^{-1}$ to $18 \mathrm{Tg} \mathrm{yr}^{-1}$ for year 2000 (Textor et al., 2006). These uncertainties may lead to differences of a factor of two or more in the simulated monthly averaged concentrations among different models, and between simulated and observed concentrations (Textor et al., 2006). The lack of comprehensive measurement data sets hampers evaluation efforts and the improvement of seasalt models and related parameterizations. For a given region 
and a given time period, only a few coincident measurements of surface concentration, aerosol optical depth (AOD), and particle-size distribution are available, and a few emission and deposition flux estimates at specific sites and temporal intervals can be found in literature. Additional difficulties arise from biases in satellite retrievals, particularly in the most important sea-salt production regions (e.g. Jaeglé et al., 2011).

Several approaches are typically used to parameterize the sea-salt emission process, from semi-empirical combinations of whitecap factorization and concentration measurements (Monahan et al., 1986; Smith et al., 1993; Smith and Harrison, 1998; Andreas, 1998; Hoppel et al., 2002; Gong, 2003; Petelski et al., 2005; Mårtensson et al., 2003; Clarke et al., 2006; Caffrey et al., 2006; Jaeglé et al., 2011; Fan and Toon, 2011), to empirical methods such as the use of concentration vertical profiles from aircraft observations (Reid et al., 2001). Parameterizations of sea-salt emission fluxes may account for different production mechanisms (e.g. bubble bursting, spume cutting), which may depend on different meteorological parameters. The most used parameter is wind speed at $10 \mathrm{~m}\left(U_{10}\right)$, but there have also been attempts to include dependencies on sea surface temperature (SST), wave height, increasing/decreasing wind, salinity and other parameters. Exhaustive reviews of these efforts and their performance can be found in Lewis and Schwartz (2004), O'Dowd and de Leeuw (2007), de Leeuw et al. (2011), and Grythe et al. (2013). The above-mentioned parameterizations are assumed for the open ocean. Production in the surf-zone represents an additional open issue (de Leeuw et al., 2000).

The high hygroscopicity of sea-salt requires water uptake schemes based on prescribed growth factors (Chin et al., 2002) or equations (Gerber, 1985; Ghan et al., 2001) or explicit calculations of the condensed aerosol water (Vignati et al., 2004). However, their performance is hard to assess and it remains an open topic for aerosol modeling (Textor et al., 2006).

In this contribution, we investigate the uncertainties associated with sea-salt, open-ocean emission schemes. We use a new sea-salt module coupled online to the multiscale NMMB/BSC Chemical Transport Model (NMMB/BSCCTM) (Pérez et al., 2011; Haustein et al., 2012; Jorba et al., 2012), developed at the Barcelona Supercomputing Center in collaboration with NOAA/National Centers for Environmental Prediction (NCEP) and the NASA Goddard Institute for Space Studies. Its meteorological core, the Non-hydrostatic Multiscale Model (NMMB) (Janjic, 2005; Janjic and Black, 2007; Janjic et al., 2011; Janjic and Gall, 2012) allows for a bridging of the gap between global, regional, and local scales by using consistent dynamics and physics formulations.

In Sects. 2 and 3 we present the modeling system along with details of the sea-salt module development. We implement five emission parameterizations following the whitecap approach, in order to investigate this major source of uncertainty. Particular attention is given to the description of spume particles production and to the dependence of emissions upon SST. In Sect. 4 we present the observational data sets used for the evaluation of the global simulations. Results and discussion of $5 \mathrm{yr}$ simulations (2002-2006) are presented in Sect. 5. Evaluation is performed against cruise data from the NOAA/PMEL Laboratory, sea-salt concentration monthly climatologies from the University of Miami Ocean Aerosol Network, and monthly averaged measurements from distributed AERONET sun photometers. Our results are also compared with other recent model studies, such as Jaeglé et al. (2011) and Tsigaridis et al. (2013).

\section{Modeling background}

The NMMB/BSC-CTM is a fully online chemical transport model coupling the atmospheric equations of NMMB with the gas-phase and aerosol continuity equations of BSC-CTM. At the present stage of development aerosol species included in the model are dust and sea-salt. The implementation and evaluation of other globally relevant aerosols is underway. Details on the dust aerosol module and gas-phase module can be found in Pérez et al. (2011) and Jorba et al. (2012), respectively. According to the features of its unified meteorological core, NMMB/BSC-CTM was conceived for short- and mediumrange forecasting for a wide range of spatial scales as well as for climate studies (http://www.bsc.es/earth-sciences/ mineral-dust/nmmbbsc-dust-forecast). Due to its fully online coupling, several feedback processes among gases, aerosol particles and radiation are taken into account by the model. In particular, the radiative effect of aerosols is considered, while cloud-aerosol interactions are neglected at present. The online coupling of aerosol optical properties and gas-phase photolysis reactions is also under development.

\subsection{The NCEP non-hydrostatic multiscale model (NMMB)}

The NMMB is the meteorological core of the modeling system, allowing simulations of scales ranging from global to large eddy simulations (LES) in global and regional domains. The regional NMMB has been used at NCEP as the regional North American Mesoscale (NAM) model since October 2011. The global model is formulated on the latitudelongitude grid, by applying conservative polar boundary conditions and polar filtering, slowing down the tendencies of basic dynamic variables (Janjic, 2009; Janjic and Gall, 2012). Rotated latitude-longitude grids are employed for regional simulations in order to obtain more uniform grid distances. In both cases, the horizontal discretization is performed on the Arakawa B-grid. In the vertical, the general hybrid sigmapressure coordinate (Simmons and Burridge, 1981) is used with the Lorenz staggering. The "isotropic" horizontal finite volume differencing technique assures the conservation 
of a number of dynamical and quadratic quantities (among these, energy and enstrophy). More details about the numerical schemes of the NMMB can be found in Janjic (1977, 1979, 1984, 2003) and in Janjic et al. (2001, 2011).

A variety of physical schemes are implemented in the model. A list of these parameterizations and their respective references were presented in Pérez et al. (2011) and further details can be found in Janjic (1990, 1994, 1996, 2001). For our purposes, we shortly recall the parameterizations involved in the sea-salt aerosol cycle, i.e., surface layer, gridscale cloud microphysics, convective adjustment and precipitation, and radiation schemes. Boundary layer, and free atmosphere turbulence are parameterized using the MellorYamada-Janjic (MYJ) turbulence closure scheme (Mellor and Yamada, 1982; Janjic, 2001). In the surface layer the Monin-Obukhov similarity theory (Monin and Obukhov, 1954) is applied (Janjic, 1996) in combination with a viscous sub-layer parameterization over oceans (Janjic, 1994). The wind speed at $10 \mathrm{~m}\left(U_{10}\right)$, which is the key parameter of sea-salt production schemes is computed consistently with the surface layer parameterization. The friction velocity $u^{*}$ is computed as the square root of the surface layer vertical momentum transport.

Grid-scale clouds are parameterized with the scheme of Ferrier et al. (2002) including 5 prognostic cloud variables. The relevant quantities for the coupling with aerosol processes are the mixing ratios of both liquid and ice cloud water and their conversion rates to precipitation. The Betts-MillerJanjic convective adjustment scheme (Betts, 1986; Betts and Miller, 1986; Janjic, 1994, 2000) is used for sub-gridscale clouds. Using conservational constraints, the convective clouds are represented by reference humidity and temperature profiles. Both water vapor mixing ratio and temperature are relaxed toward reference values within a convection time step. In the case of deep convection, the reference profiles and the relaxation time are governed by the cloud efficiency $E$ which depends on convective regime. This is a nondimensional parameter obtained as a combination of entropy change, precipitation, and mean cloud temperature (Janjic, 1994, 2000). The shallow convection parameterization closure uses the constraint that the entropy change must be non-negative Janjic $(1994,2000)$. The NMMB uses the operational Geophysical Fluid Dynamics Laboratory (GFDL) radiation package, which includes shortwave (Lacis and Hansen, 1974) and longwave (Fels and Schwarzkopf, 1975) schemes. Since the coupling with aerosols is not allowed by the operational GFDL scheme, the Rapid Radiative Transfer Model (RRTM) (Mlawer et al., 1997) was implemented in the model (Pérez et al., 2011). By using RRTM, it is possible to couple radiation (both long- and shortwave) and aerosols by providing aerosol optical depth, asymmetry factor, and single-scattering albedo.

\subsection{The BSC-CTM dust module (BSC-DUST)}

The development of the sea-salt module follows the implementation of BSC-DUST (Pérez et al., 2011; Haustein et al., 2012), i.e., the dust module of NMMB/BSC-CTM. BSC-DUST includes 8 transport bins ranging from $0.1 \mu \mathrm{m}$ to $10 \mu \mathrm{m}$ in dry radius. Within each transport bin a log-normal time-invariant sub-bin distribution is assumed. The processes considered by the module are dust emission, horizontal and vertical advection, horizontal diffusion and vertical transport by turbulence and convection, dry deposition and sedimentation, and wet removal including in- and below- cloud scavenging from grid- and sub-grid scale clouds. Water uptake was not considered. Given the strong uncertainties on the activation properties of dust, solubility is obtained by applying an intermediate hypothesis between pure hydrophobic and pure hydrophilic aerosol. Both global and regional simulations of dust optical depth have been exhaustively evaluated in Pérez et al. (2011) and Haustein et al. (2012). In this contribution, the model coarse AOD is calculated from the dust and sea-salt components allowing the use of AERONET stations affected by dust to be included in the evaluation.

\section{The sea-salt module}

Sea-salt is assumed to be externally mixed with dust and the continuity equation is solved for 8 prognostic size-sections:

$\partial_{t} q_{k}+(\boldsymbol{v} \cdot \nabla)_{h} q_{k}=F_{k}^{(\mathrm{emi})}-\sum_{n} F_{n, k}^{(\mathrm{sink})}+F_{k}^{(\mathrm{diff})}$,

where $q_{k}$ are the sea-salt dry mass mixing-ratios, $v$ is the wind velocity, subscript $h$ stands for horizontal operator, and $F_{k}^{(\mathrm{emi})}, F_{n, k}^{\text {(sink) }}, F_{k}^{\text {(diff) }}$ represent sea-salt production, sink/mixing, and turbulent diffusion terms, respectively. Advection and diffusion are analogous to those of moisture in NMMB (Janjic, 2009). The production term is detailed in Sect. 3.1 and sink processes are described in Sect. 3.2.

We assume a dry radius lower cutoff of $0.1 \mu \mathrm{m}$ in the size distribution. Upper size cutoff values depend on the production parameterization (a detailed discussion are provided in Sect. 3.1) and were fixed to $15 \mu \mathrm{m}$ to comprehensively account for all the different formation processes. Size-bins are described in Table 1. Simulated sea-salt mass and optical depth are strongly influenced by the number of size-bins adopted, due to the strong dependence of dry deposition upon particle size (Witek et al., 2011). Simulated values tend to converge above 15 size-bins, while mass loss takes place otherwise. We employ 8 size-bins which involves a mass loss of $5 \%$ (Witek et al., 2011) - a negligible quantity compared to emission uncertainties - as a trade-off for doubled computational efficiency. A sub-bin log-normal approach is assumed to calculate different momenta of particle radius, such as dry effective radius $r_{\mathrm{d}}^{\text {eff }}=<r_{\mathrm{d}}^{3}>/<r_{\mathrm{d}}^{2}>$ and volume mean radius $r_{\mathrm{d}}^{\mathrm{vm}}=\left(<r_{\mathrm{d}}^{3}>/<r_{\mathrm{d}}^{0}>\right)^{1 / 3}$. We assume the canonical 
Table 1. Sea-salt size bins and their characteristic radii. $r_{\mathrm{d}}, r_{\mathrm{d}}^{\mathrm{vm}}$, and $r_{\mathrm{d}}^{\text {eff }}$ stand for dry radius, dry volume mean radius, and effective radius, respectively.

\begin{tabular}{rrrr}
\hline bin & $r_{\mathrm{d}}(\mu \mathrm{m})$ & $r_{\mathrm{d}}^{\mathrm{vm}}(\mu \mathrm{m})$ & $r_{\mathrm{d}}^{\mathrm{eff}}(\mu \mathrm{m})$ \\
\hline 1 & $0.10-0.18$ & 0.14 & 0.14 \\
2 & $0.18-0.30$ & 0.24 & 0.24 \\
3 & $0.30-0.60$ & 0.43 & 0.45 \\
4 & $0.60-1.00$ & 0.77 & 0.79 \\
5 & $1.00-1.80$ & 1.32 & 1.36 \\
6 & $1.80-3.00$ & 2.27 & 2.32 \\
7 & $3.00-6.00$ & 3.98 & 4.13 \\
8 & $6.00-15.00$ & 7.39 & 8.64 \\
\hline
\end{tabular}

log-normal distribution of Lewis and Schwartz (2004), characterized by a geometric radius at $\mathrm{RH}=80 \%, r_{80}^{\mathrm{g}}=0.3 \mu \mathrm{m}$ and geometric standard deviation $\sigma^{\mathrm{g}}=2.8$.

\subsection{Emissions}

Strong uncertainties of up to one order of magnitude affect the estimates of sea-salt production fluxes. The most widely used technique to parameterize sea-salt emission is the socalled whitecap method, by which the flux is factorized as a product of sea-surface whitecap fraction and production per whitecap unit, both terms being affected by significant uncertainties. Parameterizations use wind-speed at $10 \mathrm{~m}\left(U_{10}\right)$, SST, atmospheric stability, sea-surface salinity, and ocean waves properties (height, age, relative direction respect to wind), for which Lewis and Schwartz (2004) and O'Dowd and de Leeuw (2007) provide useful reviews. In this study, we implement five widely used whitecap method schemes for open-ocean production (surf-zone production is neglected) with details provided in Table 2. Labels G03, M86, SM93, MA03, and J11 stand for schemes provided in Gong (2003), Monahan et al. (1986), Smith et al. (1993), Mårtensson et al. (2003), and Jaeglé et al. (2011), respectively. G03, M86, and SM93 are derived from observational data sets and only depend on $U_{10}$; MA03 is derived from laboratory experiments and includes SST effects that are size-dependent. J11 emissions are formulated by multiplying the G03 scheme by a SST-dependent function equal for all particle sizes. The function was fitted using the GEOS-CHEM model and observations. In our work, we keep the function as it was derived by Jaeglé et al. (2011). With the exception of SM93, all the implemented schemes apply the same wind speed power law $\left(U_{10}^{3.41}\right)$ in the whitecap parameterization. Consequently, we do not focus on the model sensitivity to changes in this term. MA03 was derived for a temperature interval ranging from $271 \mathrm{~K}$ to $298 \mathrm{~K}$, which does not strictly cover the annual variation of global SST. J11 is formulated for temperatures ranging from $273.15 \mathrm{~K}$ to $303.15 \mathrm{~K}$.

For our comparison, we choose schemes differing in particle size and production mechanism description. Figure 1

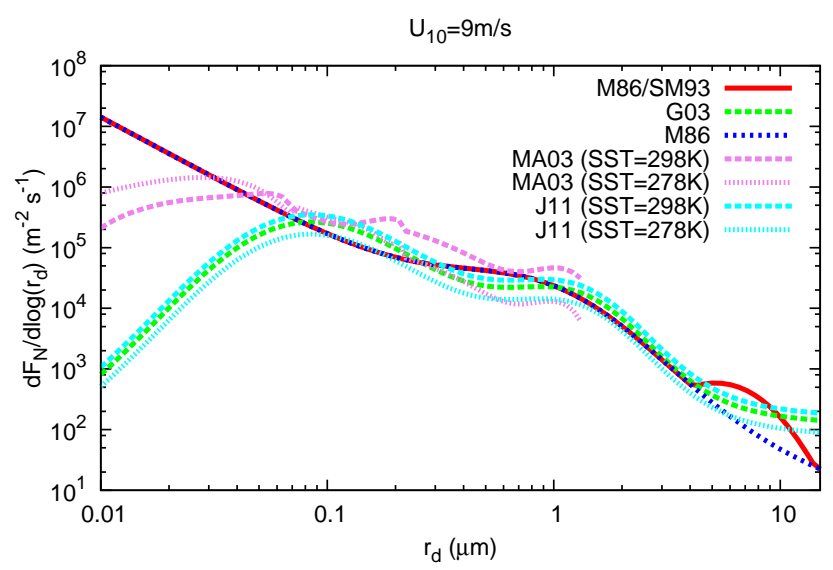

Fig. 1. Sea-salt number emission flux at $10 \mathrm{~m}$ as a function of particle dry radius with the different emission schemes (color lines). $U_{10}, r_{\mathrm{d}}$, and SST stand for wind speed at $10 \mathrm{~m}$, dry radius, and seasurface temperature, respectively.

shows that the strongest uncertainties appear for the ultrafine particles $\left(r_{\mathrm{d}}<0.1 \mu \mathrm{m}\right)$, which do not play a relevant role in the simulation of mass concentration and optical depth, and thus are beyond the scope of this work.

All considered schemes account for sea-salt formation from bubble bursting. Spume production is not described in M86 and MA03, while it is represented in SM93 (Fan and Toon, 2011), and its treatment in G03 is unclear (and, as a consequence, in J11). This leads to significant differences in emission fluxes of large particles (Fig. 1).

In addition, the above parameterizations were merged to obtain more comprehensive schemes, such as the combined M86/SM3 and MA03/M86/SM93 (Table 2). Hoppel et al. (2002) concluded that M86/SM93 may be considered as the best candidate to describe sea-salt emissions in the interval $0.15 \mu \mathrm{m}$ to $15 \mu \mathrm{m}$ in dry radius. M86/SM93 was then extended to ultrafine particles in other studies (Caffrey et al., 2006; Fan and Toon, 2011).

In this work, we also combined M86/SM93 and MA03 to account for the the SST effect upon sea-salt production. In MA03/M86/SM93, MA03 is applied within its range of validity and replaced by M86/SM93 beyond that range (i.e., for large particles with $\left.r_{\mathrm{d}}>1.4 \mu \mathrm{m}\right)$. We find a similar attempt in the work of Tsyro et al. (2011), where MA03 is combined with M86 (but not with the spume production of SM93).

We choose an upper cutoff for the particle size around the maximum value allowed by the sea-salt production parameterizations implemented in our module. To perform a consistent comparison, we consider a range of [0.1-15] $\mu \mathrm{m}$ in dry radius for all the emission schemes, which implies an extension of M86, G03, and J11 schemes beyond their formulation intervals. Because some schemes work with wet radius $r_{80}$ and others with dry radius $r_{\mathrm{d}}$, we assume $r_{80}=2 r_{\mathrm{d}}$ to obtain emission of dry particles following the water-uptake 
Table 2. Sea-salt number emission fluxes implemented in NMMB/BSC-CTM. $\mathrm{d} F_{N} / \mathrm{d} r$ fluxes in units $\left[\mathrm{m}^{-2} \mathrm{~s}^{-1} \mu \mathrm{m}^{-1}\right], \mathrm{d} F_{N} / \mathrm{d} \log (r)$ fluxes in units $\left[\mathrm{m}^{-2} \mathrm{~s}^{-1}\right] ; r_{80}$ and $r_{\mathrm{d}}$ stand for wet radius at $\mathrm{RH}=80 \%$ and dry radius in units $[\mu \mathrm{m}]$, respectively. If $r$ is used, dry or wet radius was not specified. $U_{10}$ in $\mathrm{m} \mathrm{s}^{-1}$. SST in K units. Formul. range stands for the size-range in the original formulation of each parameterization. The assumption $r_{80}=2 r_{\mathrm{d}}$ is used to merge wet and dry radius intervals. All schemes are applied in the range $r_{\mathrm{d}} \in[0.1-15] \mu \mathrm{m}$.

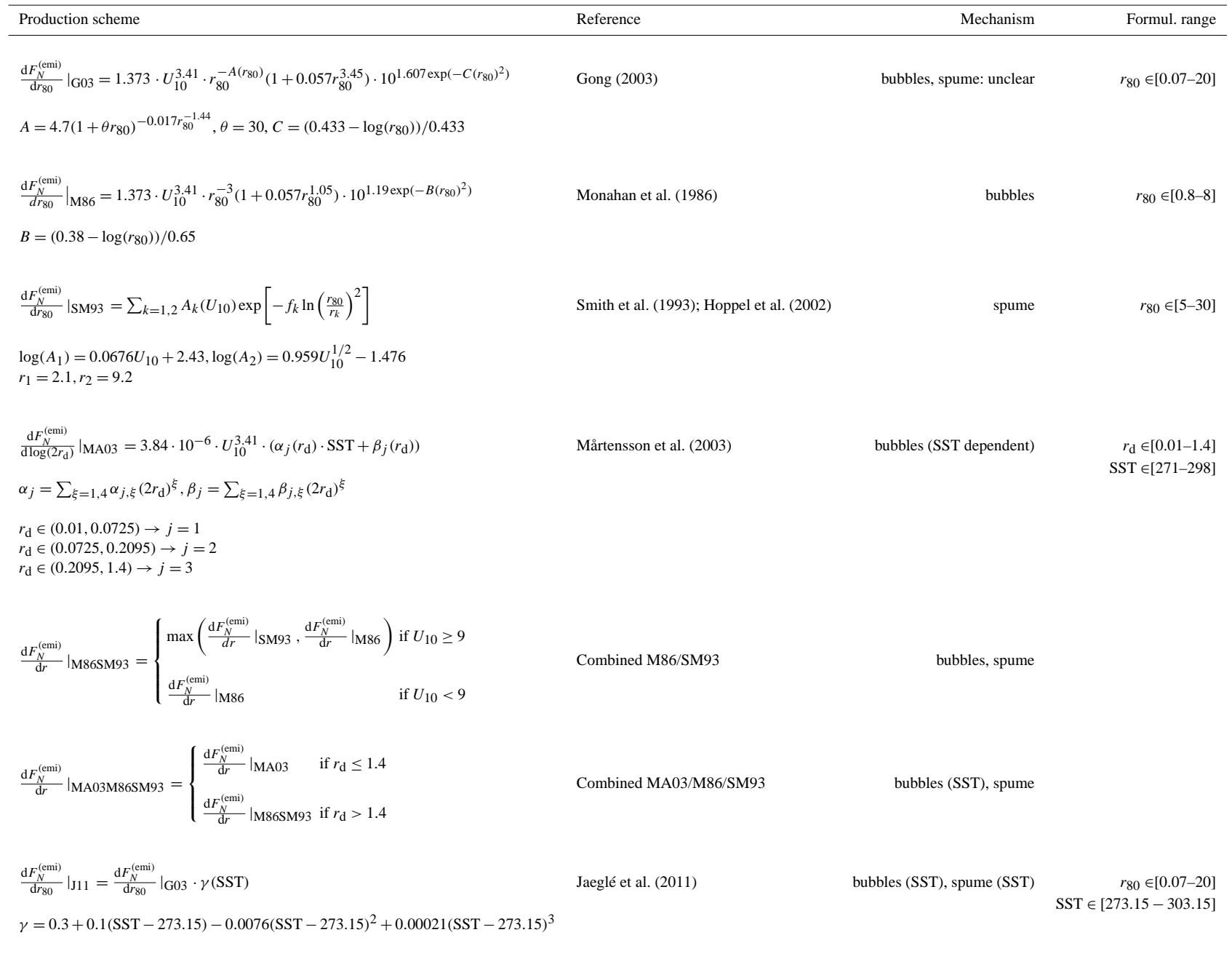

treatment (detailed in Sect. 3.2). Mass emission fluxes $F^{(\mathrm{emi})}$ are calculated from number fluxes $F_{N}^{(\mathrm{emi})}$ as

$F_{k}^{(\mathrm{emi})}=\int_{\text {bin }-k} \frac{\mathrm{d} F_{N}^{(\mathrm{emi})}}{\mathrm{d} r_{\mathrm{d}}} \cdot \frac{4 \pi}{3} \rho_{\mathrm{d}} r_{\mathrm{d}}^{3} \mathrm{~d} r_{\mathrm{d}}$.

The emission mechanism is not explicitly coupled with the viscous sub-layer of the NMMB. However, the calculation of friction velocity and wind speed at $10 \mathrm{~m}$ depends on the viscous sub-layer scheme in the surface layer.

\subsection{Water uptake}

The sea-salt life cycle is strongly affected by water uptake. Hygroscopic growth may increase particles' radii by a factor of 4 or more. Following Chin et al. (2002) we introduced prescribed RH-dependent growth factors $\phi(\mathrm{RH})=r_{\mathrm{w}} / r_{\mathrm{d}}$, de- rived from the Global Aerosol Data Set of Köepke et al. (1997) and the database of d'Almeida (1991) (Table 3). $r_{\mathrm{w}}$ and $r_{\mathrm{d}}$ are the wet and the dry particle radius, respectively. We assume the same factors for any radius-moment representation, such as effective and volume-mean radii.

Given $\phi(\mathrm{RH})$, the water-uptake process is fully described by extending any dry particle parameter to its respective wet value. In particular we obtain wet particle radius and density as

$r_{\mathrm{d}} \rightarrow r_{\mathrm{w}}=\phi \cdot r_{\mathrm{d}}$

$\rho_{\mathrm{d}} \rightarrow \rho_{\mathrm{w}}=f_{\mathrm{d}} \rho_{\mathrm{d}}+\left(1-f_{\mathrm{d}}\right) \rho_{\mathrm{water}}$,

where $\rho_{\text {water }}$ is the density of water and $f_{\mathrm{d}}$ is the volume fraction of dry aerosol $\left(f_{\mathrm{d}}=\phi^{-3}\right)$. The dry sea-salt density is assumed $\rho_{\mathrm{d}}=2160 \mathrm{~kg} \mathrm{~m}^{-3}$ for every size-bin. By using this simplified approach, all aerosol processes affected by 
Table 3. Sea-salt hygroscopic growth factors $\phi=r_{\mathrm{W}} / r_{\mathrm{d}}$ at different ambient relative humidity (RH) values. $r_{\mathrm{W}}$ and $r_{\mathrm{d}}$ stand for dry and wet radius, respectively.

\begin{tabular}{cc}
\hline $\mathrm{RH}(\%)$ & $\phi$ \\
\hline$<50$ & 1.0 \\
$50-70$ & 1.6 \\
$70-80$ & 1.8 \\
$80-90$ & 2.0 \\
$90-95$ & 2.4 \\
$95-99$ & 2.9 \\
$>99$ & 4.8 \\
\hline
\end{tabular}

hygroscopic growth are easily reformulated by extending the parameterizations used in the dust module (dry aerosol) to the wet-particle case, i.e., by applying Eqs. (3) and (4). In the following we present a short review of the parameterizations used in the aerosol module of NMMB/BSC-CTM, pointing out the extension to wet particles in the sink and mixing terms. A more detailed description of each scheme can be found in Pérez et al. (2011). When not otherwise specified we refer to $r_{\mathrm{d}}^{\mathrm{vm}}$ as $r_{\mathrm{d}}$ for brevity.

\subsection{Deposition and convective mixing}

Sedimentation is governed by the gravitational settling velocity $v_{\mathrm{g}, k},(\phi)$, calculated for each size-bin $k$ following the Stokes-Cunningham approximation. $v_{\mathrm{g}, k},(\phi)$ depends on the particle size and thus on the water uptake.

The dry deposition velocity $v_{\mathrm{dep}, k}(\phi)$, acting at the bottom layer, is parameterized following Zhang et al. (2001). The dependence on $\phi$ is introduced in the surface resistance calculation, which accounts for particle size and density (Slinn, 1982).

Wet scavenging fluxes are parameterized both for gridscale (stratiform) and sub-grid scale (convective) clouds. Incloud scavenging flux is parameterized using a solubility parameter $\epsilon_{k}$ that is defined as the fraction of aerosol contained in cloud which may eventually precipitate. For sea-salt particles, $\epsilon_{k}$ is obtained from Zakey et al. (2006). Since the values found in Zakey et al. (2006) for dust represent an intermediate between pure hydrophobic and pure hydrophilic hypothesis, we assume $\epsilon_{\mathrm{ss}, k}=2 \epsilon_{\mathrm{du}, k}$. This calculation of $\epsilon_{\mathrm{ss}, k}$ is consistent with the values used in other state-of-the-art models (see for ex. the sensitivity study in Fan and Toon, 2011). Because small particles are more probable candidates to act as cloud condensation nuclei, $\epsilon_{\mathrm{ss}, k}$ decreases with size (see Table 4). Grid-scale below cloud scavenging is parameterized following Slinn (1984) in which capture efficiencies $E_{k}(\phi)$ depend on the wet radius and density of the aerosol particles.

For sub-grid (convective) clouds, the scavenging fluxes are coupled with the Betts-Miller-Janjic scheme (BMJ) of the NMMB. The convective in-cloud scavenging parameterization employs solubility factors $\epsilon(k, \phi)$ as well. After
Table 4. Sea-salt solubility factors $\epsilon_{\mathrm{ss}, k}$ for each size-bin $k$.

\begin{tabular}{cc}
\hline$k$ & $\epsilon_{\mathrm{ss}}$ \\
\hline 1 & 0.6 \\
2 & 0.6 \\
3 & 0.6 \\
4 & 0.3 \\
5 & 0.3 \\
6 & 0.1 \\
7 & 0.1 \\
8 & 0.1 \\
\hline
\end{tabular}

the in-cloud scavenging, the remaining sea-salt is assumed vertically mixed by performing a conservative relaxation towards reference profiles. The parameterization of sub-grid below-cloud scavenging is analogous to the case of grid-scale clouds. Within shallow non-precipitating convective clouds sea-salt is homogeneously mixed within the cloud.

\subsection{AOD calculation}

In order to calculate the sea-salt optical depth, extinction efficiencies $Q_{\lambda, k}^{\text {ext }}$ are computed with the Mie-theory solving algorithm of Mishchenko et al. (2002) for each size-bin $k$ and each RH range (Fig. 2). Spherical homogeneous particles are assumed. The refractive indices were derived from the Global Aerosol Data Set (GADS) (Köepke et al., 1997). Extinction efficiencies also depend on the sub-bin log-normal geometric parameters $r^{\mathrm{g}}$ and $\sigma^{\mathrm{g}}$ (Lewis and Schwartz, 2004). The optical depth is obtained as

$\tau_{\lambda, k}=\beta_{\lambda, k} \tilde{M}_{\mathrm{d}, k}$,

where $\tilde{M}_{\mathrm{d}, k}$ is the layer dry mass loading of each bin and $\beta_{\lambda, k}$ is a mass extinction coefficient which accounts for water uptake:

$\beta_{\lambda, k}=\frac{3 Q_{\lambda, k}^{\mathrm{ext}}\left(\phi, r_{\mathrm{w}}^{\mathrm{g}}, \sigma_{\mathrm{w}}^{\mathrm{g}}\right)}{4 r_{\mathrm{w}, k}^{\mathrm{eff}} f_{\mathrm{d}}(\phi) \rho_{\mathrm{d}, k}}$.

The algorithm of Mishchenko et al. (2002) also provides single-scattering albedo and asymmetry factor for radiative calculations. The total sea-salt optical depth is equal to the sum over all bins:

$\tau_{\lambda, T}=\sum_{k=1,8} \tau_{\lambda, k}$.

The coarse sea-salt optical depth is calculated with a lower cutoff value of $0.6 \mu \mathrm{m}$ (the AERONET submicron cutoff) of the wet particle radius. In our description, this value is equivalent to a lower cutoff of the dry particle radius $\bar{r}_{\mathrm{d}}$ given by

$\bar{r}_{\mathrm{d}}=0.6 \mu \mathrm{m} / \phi(\mathrm{RH})$. 
At maritime atmospheric conditions $(\mathrm{RH}=80 \%)$, the submicron bins significantly contribute to the coarse AOD. Subbin contributions to the coarse optical depth are calculated assuming the log-normal distribution of Lewis and Schwartz (2004). Another useful parameter for model evaluation is the resulting AOD (total and coarse) from both sea-salt and dust. Because of their external mixing, we assume

$\tau_{\mathrm{ss}+\mathrm{du}, \lambda}=\tau_{\mathrm{ss}, \lambda}+\tau_{\mathrm{du}, \lambda}$,

where the subscripts ss and du respectively refer to sea-salt and dust.

\section{Observational data}

Figure 3 displays the location of measurement sites and cruise measurement trajectories used in the model evaluation. Names and coordinates of the sites are listed in Table 5. Quantities evaluated are sea-salt surface concentrations and AOD. For the station data we use monthly climatologies to compare with our simulated $5 \mathrm{yr}$ period (2002-2006).

We consider AERONET Sun photometer measurements as the reference to evaluate the modeled sea-salt AOD. Even if algorithms tend to minimize biases due to cloud cover and other effects (e.g. Zhang and Reid, 2006), estimates from satellites remain highly uncertain and are not used in this contribution. Satellite overestimation can reach up to 0.07 in island stations compared to monthly AERONET-derived AOD (Jaeglé et al., 2011). At certain latitudes, the bias between satellite and ship AOD measurements may range from -0.2 to +0.2 (Smirnov et al., 2011). These biases exceed the typical sea-salt AOD value in the remote marine environment $(\sim 0.07$, see Smirnov et al., 2011). AOD measurements from the AERONET Maritime Aerosol Network (MAN) are not used in this work because of complexities in disentangling sea-salt and dust contributions from other aerosol species (such as carbonaceous and sulfate aerosols) that are currently neglected in our model.

\subsection{NOAA/PMEL cruises}

Sea-salt cruise measurements are considered, specifically ion concentrations from two cruises of the NOAA Pacific Marine Environmental Laboratory (PMEL): the AEROSOLS99 and INDian Ocean EXperiment (AEROINDOEX) in 1999 spanning the Atlantic and the Indian Oceans and the first Aerosol Characterization Experiment (ACE1) in 1995 crossing the Pacific Ocean. Concentrations of both $\mathrm{Na}^{+}$and $\mathrm{Cl}^{-}$ were measured by ion chromatography (Quinn et al., 1998) at $18 \mathrm{~m}$ above the sea surface. The experimental aerodynamic cutoff diameter was $10 \mu \mathrm{m}$ for all cruises. Instruments were kept at constant $\mathrm{RH}$ values during measurements. Based on these values, Jaeglé et al. (2011) assumed a dry radius cutoff of $3 \mu \mathrm{m}$ for AEROINDOEX and ACE1. Hence, we use the first 6 dry model bins for the comparison. The ACE1 and

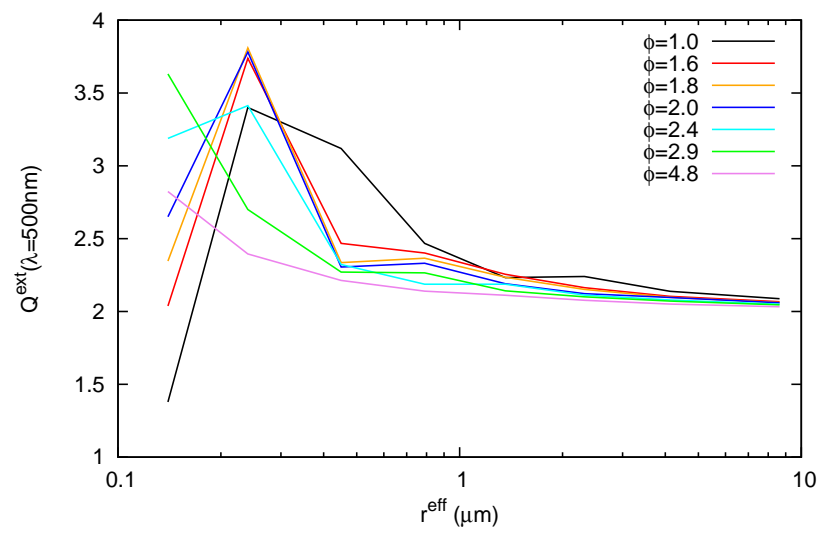

Fig. 2. Sea-salt extinction efficiency $\left(Q^{\text {ext }}\right)$ at $\lambda=500 \mathrm{~nm}$, depending on water-uptake growth factors $\phi$ of Table 3 . The values are plotted as function of the effective radius of each size-bin $(r$ eff , see Table 1).

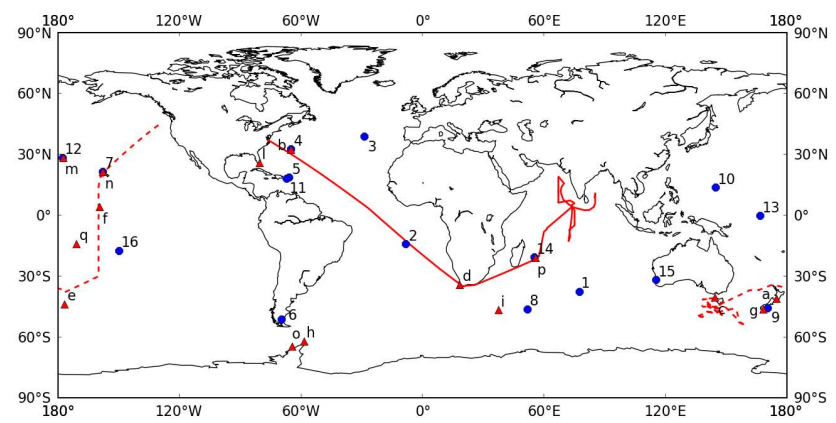

Fig. 3. Observational data sets used for the model evaluation: blue circles refer to AOD measurements from AERONET, red triangles to surface concentration measurements from the U-MIAMI network; red lines refer to cruise measurement trajectories from AEROINDOEX (solid line), and ACE1 (dashed line).

AEROINDOEX data sets also provide wind speed measurements at $33 \mathrm{~m}$ and $14 \mathrm{~m}$ above sea surface, respectively.

The spatial scale of the cruise measurements is around $600 \mathrm{~km}$ since they were averaged over temporal windows ranging from 2 to $24 \mathrm{~h}$; mean ship speeds were around $24 \mathrm{~km} \mathrm{~h}^{-1}$.

\subsection{U-MIAMI surface concentrations}

The U-MIAMI network supplied aerosol measurements from around 35 stations worldwide between the early 1980s and 1996 (Savoie and Prospero, 1977). Aerosols were collected with high-volume filter samplers and different measurement protocols were employed depending on the measurement site. We use climatologies from 15 stations (Fig. 3 and Table 5). These stations grant good data quality and are not affected by surf-zone production (J. Prospero, personal communication, 2012). The observed sea-salt mass concentrations $\left(\mu \mathrm{g} \mathrm{m}^{-3}\right)$ were computed as $\mathrm{SS}=\mathrm{Cl}^{-}+1.47 \mathrm{Na}^{+}$ 
Table 5. List of the observational sites used in this work, classified by network.

\begin{tabular}{|c|c|c|c|c|}
\hline Code & Database & Station & lat & lon \\
\hline \multicolumn{5}{|c|}{ AOD500 nm } \\
\hline 1 & AERONET & Amsterdam Island & $37.81^{\circ} \mathrm{S}$ & $77.57^{\circ} \mathrm{E}$ \\
\hline 2 & AERONET & Ascension Island & $7.98^{\circ} \mathrm{S}$ & $14.41^{\circ} \mathrm{W}$ \\
\hline 3 & AERONET & Azores & $38.53^{\circ} \mathrm{N}$ & $28.63^{\circ} \mathrm{W}$ \\
\hline 4 & AERONET & Bermuda & $32.37^{\circ} \mathrm{N}$ & $64.70^{\circ} \mathrm{W}$ \\
\hline 5 & AERONET & Cape San Juan & $18.38^{\circ} \mathrm{N}$ & $65.62^{\circ} \mathrm{W}$ \\
\hline 6 & AERONET & Ceilap-RG & $51.60^{\circ} \mathrm{S}$ & $69.32^{\circ} \mathrm{W}$ \\
\hline 7 & AERONET & Coconut Island & $21.43^{\circ} \mathrm{N}$ & $157.79^{\circ} \mathrm{W}$ \\
\hline 8 & AERONET & Crozet Island & $46.43^{\circ} \mathrm{S}$ & $51.85^{\circ} \mathrm{E}$ \\
\hline 9 & AERONET & Dunedin & $45.86^{\circ} \mathrm{S}$ & $170.51^{\circ} \mathrm{E}$ \\
\hline 10 & AERONET & Guam Island & $13.43^{\circ} \mathrm{N}$ & $144.80^{\circ} \mathrm{E}$ \\
\hline 11 & AERONET & arguera & $17.97^{\circ} \mathrm{N}$ & $67.04^{\circ} \mathrm{W}$ \\
\hline 12 & AERONET & Midway Island & $28.21^{\circ} \mathrm{N}$ & $177.38^{\circ} \mathrm{W}$ \\
\hline 13 & AERONET & Nauru & $0.52^{\circ} \mathrm{S}$ & $166.92^{\circ} \mathrm{E}$ \\
\hline 14 & AERONET & Reunion Island & $20.88^{\circ} \mathrm{S}$ & $55.48^{\circ} \mathrm{E}$ \\
\hline 15 & AERONET & Rottnest Island & $32.00^{\circ} \mathrm{S}$ & $115.50^{\circ} \mathrm{E}$ \\
\hline 16 & AERONET & Tahiti & $17.58^{\circ} \mathrm{S}$ & $149.61^{\circ} \mathrm{W}$ \\
\hline \multicolumn{5}{|c|}{ SURFACE CONCENTRATIONS } \\
\hline $\mathrm{a}$ & $\mathrm{U}$ & & $41.28^{\circ} \mathrm{S}$ & $7^{\circ} \mathrm{E}$ \\
\hline $\mathrm{b}$ & U-1 & & $7^{\circ} \mathrm{N}$ & $7^{\circ} \mathrm{W}$ \\
\hline c & U-MIAMI & Cape Grim & $40.68^{\circ} \mathrm{S}$ & $144.68^{\circ} \mathrm{E}$ \\
\hline $\mathrm{d}$ & U-MIAMI & Cape Point & $34.35^{\circ} \mathrm{S}$ & $18.48^{\circ} \mathrm{E}$ \\
\hline $\mathrm{e}$ & U-MIAMI & Chatam Island & $34.92^{\circ} \mathrm{S}$ & $176.50^{\circ} \mathrm{W}$ \\
\hline $\mathrm{f}$ & U-MIAMI & Fanning Island & $3.92^{\circ} \mathrm{N}$ & $159.33^{\circ} \mathrm{W}$ \\
\hline $\mathrm{g}$ & U-MIAMI & Invercargill & $46.43^{\circ} \mathrm{S}$ & $168.35^{\circ} \mathrm{E}$ \\
\hline $\mathrm{h}$ & U-MIAMI & King George Island & $62.18^{\circ} \mathrm{S}$ & $58.30^{\circ} \mathrm{W}$ \\
\hline $\mathrm{i}$ & U-MIAMI & Marion Island & $46.92^{\circ} \mathrm{S}$ & $37.75^{\circ} \mathrm{E}$ \\
\hline 1 & U-MIAMI & Miami & $25.75^{\circ} \mathrm{N}$ & $80.25^{\circ} \mathrm{W}$ \\
\hline $\mathrm{m}$ & U-MIAMI & Midway Island & $28.22^{\circ} \mathrm{N}$ & $177.35^{\circ} \mathrm{W}$ \\
\hline $\mathrm{n}$ & U-MIAMI & Oahu & $21.33^{\circ} \mathrm{N}$ & $157.70^{\circ} \mathrm{W}$ \\
\hline o & U-MIAMI & Palmer & $64.77^{\circ} \mathrm{S}$ & $64.05^{\circ} \mathrm{W}$ \\
\hline $\mathrm{p}$ & U-MIAMI & Reunion Island & $21.17^{\circ} \mathrm{S}$ & $55.83^{\circ} \mathrm{E}$ \\
\hline $\mathrm{q}$ & U-MIAMI & American Samoa & $14.25^{\circ} \mathrm{S}$ & $170.58^{\circ} \mathrm{W}$ \\
\hline
\end{tabular}

following Quinn and Bates (2005) where both $\mathrm{Cl}^{-}$and $\mathrm{Na}^{+}$measurements were available, and as $\mathrm{SS}=3.252 \mathrm{Na}^{+}$, where only $\mathrm{Na}^{+}$concentrations were supplied (J. Prospero, personal communication, 2012). Since U-MIAMI measurements are not constrained by an upper cutoff radius, we perform the comparison with the complete set of model bins.

\subsection{AERONET AOD}

The AEROsol RObotics NETwork (AERONET) provides automatic ground-based observations from sun photometers in a large number of stations around the globe (Holben et al., 1998; Smirnov et al., 2000). The accuracy of AERONET sun photometers is 0.01 for AOD (Holben et al., 1998; Smirnov et al., 2000). We considered a set of 16 seasalt-dominated stations as proposed by Jaeglé et al. (2011) (Fig. 3 and Table 5). The three requirements fulfilled by the stations are sea-salt contributions to the total AOD greater than $50 \%$ as predicted by GEOS-CHEM model, availability of Level 2 quality-assured data for all the considered time ranges, and at least $3 \mathrm{yr}$ of data supporting the monthly climatologies. The evaluation is performed against monthly climatologies of the AOD at $500 \mathrm{~nm}$. In particular, we focus on the AOD coarse fraction, therefore limiting the influence of fine aerosol species.

\section{Results and discussion}

\subsection{Experimental setup}

We performed global simulations between 2002 and 2006 and additional simulations covering the temporal windows of the cruises. The horizontal resolution used is $1^{\circ} \times 1.4^{\circ}$. 24 vertical layers are employed and the dynamics time step is $\Delta t=120 \mathrm{~s}$. Meteorological conditions are initialized every $24 \mathrm{~h}$ using the NCEP final analyses (FNL) at $1^{\circ} \times 1^{\circ}$ for year $\geq 2000$ and the NCEP Global Data Assimilation System analysis (GDAS) at $2.5^{\circ} \times 2.5^{\circ}$ prior to year 2000 . A spinup of 1 month for sea-salt is assumed at the beginning of each simulated period. The model output is taken every $6 \mathrm{~h}$ to calculate monthly averages and every $1 \mathrm{~h}$ when comparing with cruise observations.

The five implemented emission schemes are compared with comprehensive data sets of observations dispersed over the globe. The dust AOD is indicated with the label DU.

Feedback processes between aerosols and radiation are not considered in any of the simulations.

At each evaluation site we also compare the simulated wind speed with a $30 \mathrm{yr}$ climatology (1981-2010) derived from the NCEP/NCAR reanalysis data set (Kalnay et al., 1996) to evaluate the representativeness of our $5 \mathrm{yr}$ wind speed climatology.

\subsection{Global sea-salt distribution and total budgets}

Fig. 4 displays the global distribution of simulated sea-salt production, surface concentration, and AOD at $500 \mathrm{~nm}$ in January and August with M86/SM93. We observe a pronounced asymmetry in the summer-to-winter variation between the two hemispheres and four large regions of maximum production. The two largest monthly peaks are found in regions with enhanced westerlies, i.e., beyond the horse latitudes (lat $>30^{\circ} \mathrm{N}$ and lat $<30^{\circ} \mathrm{S}$ ). Also two local maxima can be observed in correspondence with the trade winds, next to the intertropical convergence zone (around $10^{\circ} \mathrm{N}$ and $10^{\circ} \mathrm{S}$ ). While sea-salt production at the southern belt only moderately changes with season, the northern belt is affected by strong variations during the year with increases in boreal winter well above $+200 \%$ with respect to boreal summer. It is well known that these seasonal fluctuations are related to the asymmetric variation of the global wind speed pattern, driven by the variation of the global atmospheric angular momentum (Sandwell and Agreen, 1984).

Sea-salt production and surface concentration over the $\mathrm{Pa}$ cific around $10^{\circ} \mathrm{N}$ is about half the values found at higher 

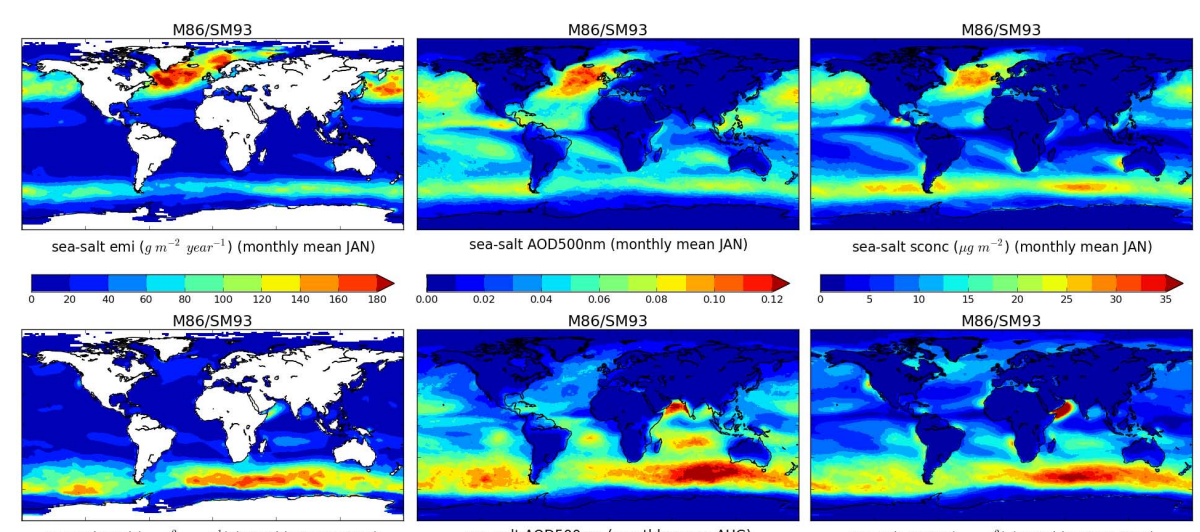

sea-salt AOD500nm (monthly mean JAN)

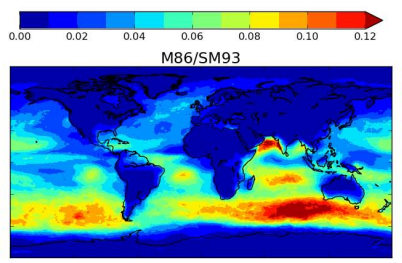

sea-salt sconc $\left(\mu g \mathrm{~m}^{-2}\right)$ (monthly mean JAN)

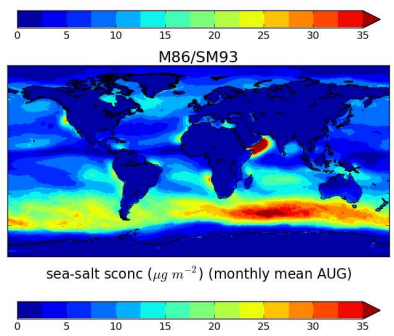

Fig. 4. Seasonal regimes of sea-salt emission (left panels), AOD at $500 \mathrm{~nm}$ (middle panels), and surface concentration (right panels) with M86/SM93. January and August averages of a 5 yr period (2002-2006) are shown. The label emi refers to emission flux, and sconc refers to surface concentration.

latitudes. Yet, the AOD reaches monthly mean values close to the global maximum. Because of the seasonal movement of the Intertropical Convergence Zone, the region around $10^{\circ} \mathrm{N}$ in the Pacific is characterized - during winter - by infrequent precipitation and low wet scavenging rate increasing particle lifetime, in contrast to the strong production belts characterized by wet extratropical cyclone activity. The RH-dependent particle size and optical properties in the model also play a relevant role in determining the AOD peaks close to the intertropical convergence zone.

Surface concentration and AOD maximum values in the Arabian Sea during the boreal summer are due to the strong southwestern winds of the monsoon circulation.

Figure 5 displays maps of annual mean sea-salt emission, surface concentration, and AOD with the five emission schemes. The two maximum production regions beyond the horse latitudes are the most sensitive to the choice of the emission scheme. G03 produces the highest concentrations with peaks above $35 \mu \mathrm{g} \mathrm{m}^{-3}$ in the southern belt and over $25 \mu \mathrm{g} \mathrm{m}^{-3}$ in the northern belt. Differences in spume production representation are clear when comparing the simple M86 with M86/SM93, for which the mean concentration is enhanced due to wind episodes exceeding the threshold $U_{10}>9 \mathrm{~m} \mathrm{~s}^{-1}$. The relative importance of the production regions changes if SST effects are included in the emission scheme. The SST dependence in MA03/M86/SM93 produces a latitudinal modulation of the emission fluxes and surface concentration with relative enhancement in the tropics and reduction elsewhere. This effect is amplified with J11, leading to a change in maximum values of surface concentration from the high-latitude belts to the tropics. In particular, an absolute maximum value above $35 \mu \mathrm{g} \mathrm{m}^{-3}$ is found over the Arabian Sea.

Sea-salt AOD patterns with M86, M86/SM93, and G03 are very similar. The southern belt dominates with peaks around $\sim 0.1$. Peak values around $\sim 0.06$ are found at high latitudes and the tropical Pacific. Relevant differences are observed with MA03/M86/SM93 for which absolute maximum values of 0.1 appear next to the intertropical convergence zone. These peaks overestimate the maximum AOD from ship measurements gathered by Smirnov et al. (2011) both in the remote tropical Pacific $(0.07$ for total AOD at $500 \mathrm{~nm})$ and the Indian Ocean (0.06, east of Madagascar). The use of the J11 scheme leads to an AOD pattern and peak values very similar to MA03/M86/SM93, with an enhancement of the SST latitudinal modulation.

Table 6 lists the annual model budgets from the different emission schemes and other recent studies. To achieve a consistent comparison, we specify values for five size intervals: all bins (ALL), fine bins up to $1 \mu \mathrm{m}$ (F1), fine bins up to $0.5 \mu \mathrm{m}$ (F2), coarse bins from $1 \mu \mathrm{m}$ to $4 \mu \mathrm{m}$ (C1), and coarse bins from $0.5 \mu \mathrm{m}$ to $4 \mu \mathrm{m}(\mathrm{C} 2)$.

Total emission, burden, and lifetime are sensitive to the parameterization of the emission flux. Lifetime ranges from 7.3i h with G03, which produces large spume particles independently from wind conditions, to $11.3 \mathrm{~h}$ with the simple M86, which neglects spume production.

Despite the decrease in total emissions, SST-dependent schemes lead to an enhancement of sea-salt lifetime, both in the case of MA03/M86/SM93 (with respect to M86/SM93) and J11 (with respect to G03). This effect was also observed in Jaeglé et al. (2011), where lifetime values are close to ours. However both fine (F1 and F2) and coarse (C1 and C2) lifetimes significantly increase with $\mathrm{J} 11$ compared to G03, in contrast to Jaeglé et al. (2011) and Tsigaridis et al. (2013). This may be related to different treatments of water uptake, deposition, and particle size distribution in the models.

With respect to AEROCOM experiments, the major difference is found in the wet deposition fraction, which is around 0.4 in our model and between 0.2 and 0.3 in AEROCOM A 

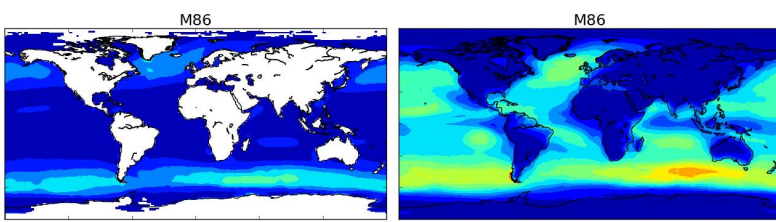

M86/SM93
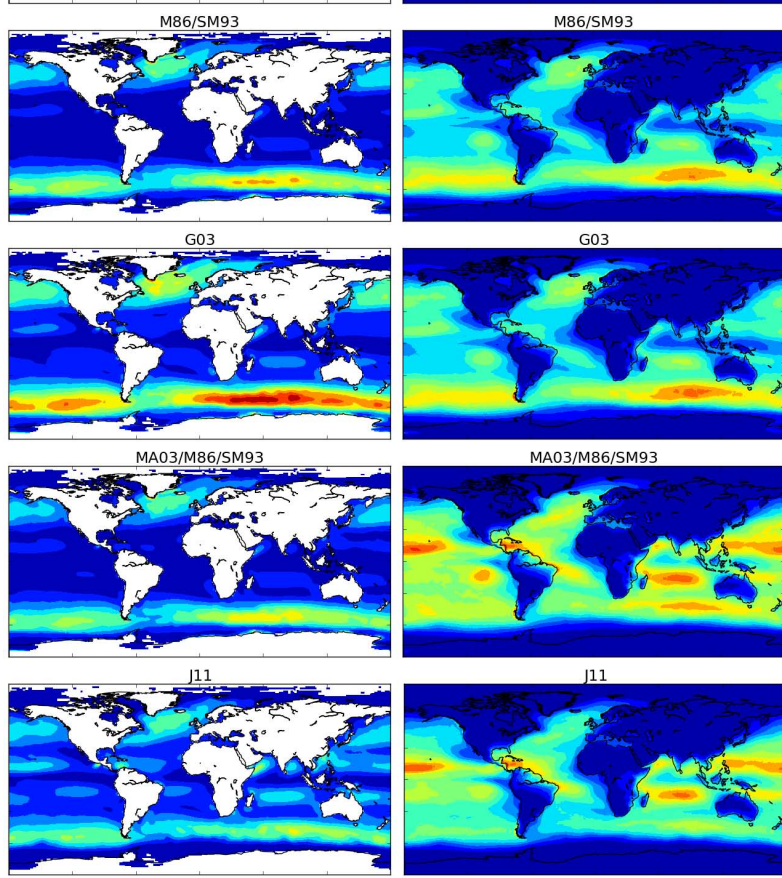

sea-salt emi $\left(g^{-2}\right.$ year $\left.{ }^{-1}\right)$ (annual mean)
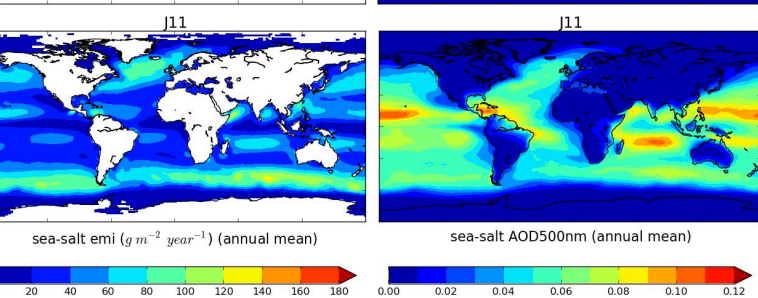

sea-salt AOD500nm (annual mean)

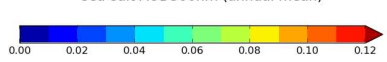

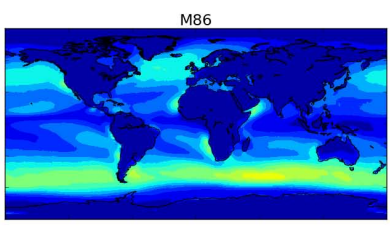
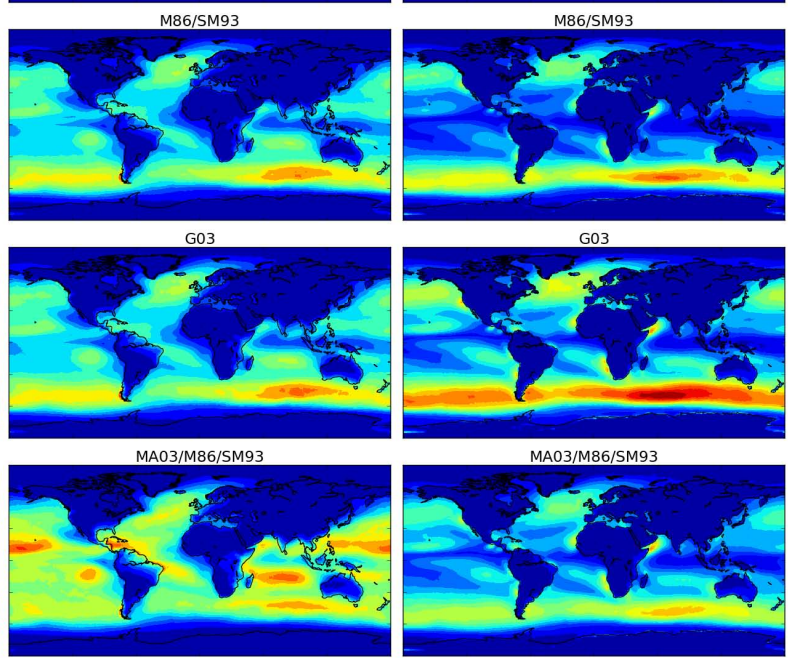
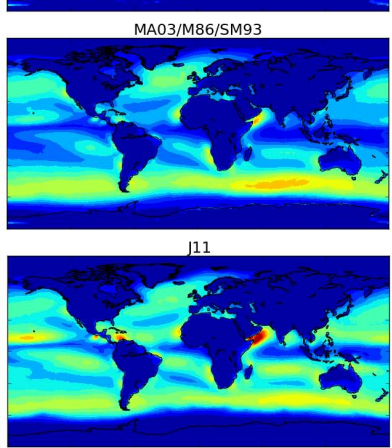

sea-salt sconc $\left(\mu g \mathrm{~m}^{-2}\right)$ (annual mean)

Fig. 5. Annual mean values of sea-salt emission (left panels), AOD at $500 \mathrm{~nm}$ (middle panels), and surface concentration (right panels), depending on the emission scheme (from top to bottom: M86, M86/SM93, G03, MA03/M86/SM93, and J11). Averages of a 5 yr period (2002-2006) are shown. The label emi refers to emission flux and sconc refers to surface concentration.

and B median models. In particular, J11 produces the most compatible value with the AEROCOM inter-model variability.

Our simulated annual mean column mass load (ranging from $5.0 \mathrm{Tg}$ to $7.2 \mathrm{Tg}$ ) is only slightly larger than the value of Jaeglé et al. (2011) and it is close to the AEROCOM Experiment A median value and about half of Experiment B (12.0 Tg) (Textor et al., 2006).

Emission is very sensitive to the upper size cutoff value and ranges from $3888 \mathrm{Tg} \mathrm{yr}^{-1}$ to $8114 \mathrm{Tg} \mathrm{yr}^{-1}$.

\subsection{Modeled surface concentrations compared with cruise data}

Cruise measurements allow a comparison with model at timescales of 2-24 h. Each measurement gathered by the vessels was averaged on space and time, thus simulated values may be affected by errors due to the adopted averaging technique. We remap the original lat/lon grid at resolution $\Delta x, \Delta y=1^{\circ}, 1.4^{\circ}$ to a coarser resolution $\left(\Delta x^{\prime}=n \Delta x\right.$, $\Delta y^{\prime}=n \Delta y$ ), matching the characteristic spatial length of the cruise under consideration. The number $n$ is defined as the smallest integer satisfying the following conditions:

$V_{\text {cruise }} \cdot \max \left(T_{\text {obs }}\right)<n \Delta x$

$V_{\text {cruise }} \cdot \max \left(T_{\mathrm{obs}}\right)<n \Delta y$,

where $V_{\text {cruise }}$ is the vessel mean speed during the cruise and $T_{\mathrm{obs}}$ is the observation duration, which is not constant. In this way, the spatial extent of each measurement is represented by a single lower resolution grid cell. We use $n=2$ for AEROINDOEX and $n=4$ for ACE1. Model outputs every $1 \mathrm{~h}$ are then averaged over each measurement period. Cruise trajectories are displayed in Fig. 3. We recall that the values shown in this comparison refer to an upper cutoff of $3 \mu \mathrm{m}$ in dry radius, thus we investigate the model's ability to simulate the concentration within the first 6 bins. In this case the M86/SM93 scheme is equivalent to M86, since the larger particles produced by spume cutting are not taken into account due to the observational cutoff.

Figures 6 and 7 show a good overall correlation for AEROINDOEX and a lower correlation for ACE1. Results are similar to those obtained in Jaeglé et al. (2011) 
Table 6. Model sea-salt global budgets and lifetimes compared with other recent studies. The label emi stands for total accumulated emission of sea-salt mass $\left(\mathrm{Tg}_{\mathrm{yr}}{ }^{-1}\right)$; wetfrac $=$ wetdep/(drydep + wetdep) where drydep accounts for both accumulated dry deposition and sedimentation $\left(\mathrm{Tg} \mathrm{yr}^{-1}\right)$ and wetdep for accumulated wet deposition $\left(\mathrm{Tg} \mathrm{yr}^{-1}\right) ;<\operatorname{load}>$ is the annual mean column mass load $\left(\mathrm{Tg}^{-1}\right)$, and lifetime $=<$ load $>/($ drydep + wetdep) (h). All quantities obtained in our work are averaged over the simulation period 2002-2006 and indicated by the label o.w. The labels ALL, F1, C1, F2, and C2 refer to different dry radius intervals $(\mu \mathrm{m})$.

\begin{tabular}{|c|c|c|c|c|c|c|c|c|c|c|c|c|c|}
\hline & \multirow[b]{2}{*}{ Study } & \multicolumn{4}{|c|}{$\operatorname{ALL}(0.1-15)$} & \multicolumn{2}{|c|}{ F1 (0.1-1) } & \multicolumn{2}{|c|}{ C1 (1-4) } & \multicolumn{2}{|c|}{ F2 $(0.1-0.5)$} & \multicolumn{2}{|c|}{ C2 (0.5-4) } \\
\hline & & emi & $<$ load $>$ & life & wetfrac & emi & life & emi & life & emi & life & emi & life \\
\hline M86 & o.w. & 3888 & 5.0 & 11.3 & 0.486 & 499 & 27.7 & 2033 & 14.7 & 75 & 28.7 & 2457 & 16.7 \\
\hline M86/SM93 & o.w. & 5440 & 5.6 & 8.9 & 0.467 & 499 & 27.7 & 2172 & 14.8 & 75 & 28.7 & 2595 & 16.8 \\
\hline G03 & o.w. & 8114 & 6.7 & 7.3 & 0.400 & 372 & 24.7 & 2465 & 12.2 & 57 & 26.1 & 2781 & 13.9 \\
\hline MA03/M86/SM93 & o.w. & 5419 & 6.5 & 10.4 & 0.466 & 266 & 32.5 & 1997 & 17.2 & 48 & 33.6 & 2215 & 19.5 \\
\hline $\mathrm{J} 11$ & o.w. & 6514 & 7.2 & 9.6 & 0.368 & 298 & 34.9 & 1979 & 16.5 & 46 & 37.1 & 2233 & 19.0 \\
\hline${\text { M } 86^{1}}^{1}$ & Tsigaridis et al. (2013) & & & & & 471 & 32.6 & 1916 & 26.6 & & & & \\
\hline $\mathrm{G}^{0} 3^{1}$ & Tsigaridis et al. (2013) & & & & & 357 & 32.6 & 2327 & 26.9 & & & & \\
\hline $\mathrm{J} 11^{1}$ & Tsigaridis et al. (2013) & & & & & 310 & 31.9 & 2019 & 26.6 & & & & \\
\hline $\mathrm{G}^{2} 3^{2}$ & Jaeglé et al. (2011) & 5200 & 4.7 & 7.9 & 0.356 & & & & & 67 & 26.2 & 2533 & 11.3 \\
\hline $\mathrm{J} 11^{2}$ & Jaeglé et al. (2011) & 4600 & 4.4 & 8.4 & 0.402 & & & & & 59 & 24.7 & 2229 & 12.0 \\
\hline AEROCOM A median ${ }^{3}$ & Textor et al. (2007) & 3830 & 6.5 & 7.2 & 0.210 & & & & & & & & \\
\hline AEROCOM A mean ${ }^{3}$ & Textor et al. (2007) & 8200 & 7.9 & 12.0 & 0.210 & & & & & & & & \\
\hline AEROCOM A stddev ${ }^{3}$ & Textor et al. (2007) & 8200 & 5.4 & 7.1 & 0.122 & & & & & & & & \\
\hline AEROCOM B median ${ }^{3}$ & Textor et al. (2007) & 7740 & 12.0 & 14.4 & 0.282 & & & & & & & & \\
\hline AEROCOM B mean ${ }^{3}$ & Textor et al. (2007) & 7720 & 12.7 & 12.0 & 0.253 & & & & & & & & \\
\hline AEROCOM B stddev ${ }^{3}$ & Textor et al. (2007) & 231 & 3.9 & 1.7 & 0.114 & & & & & & & & \\
\hline
\end{tabular}

12 modes: $r_{\mathrm{d}} \in[0.1-1] \mu \mathrm{m}$ and $r_{\mathrm{d}} \in[1-4] \mu \mathrm{m}^{2} 3$ modes: $r_{\mathrm{d}} \in[0.01-0.5] \mu \mathrm{m}, r_{\mathrm{d}} \in[0.5-4] \mu \mathrm{m}$, and $r_{\mathrm{d}} \in[4-10] \mu \mathrm{m}^{3}$ models participating in AEROCOM experiments use different parameterizations and aerosol size representations.
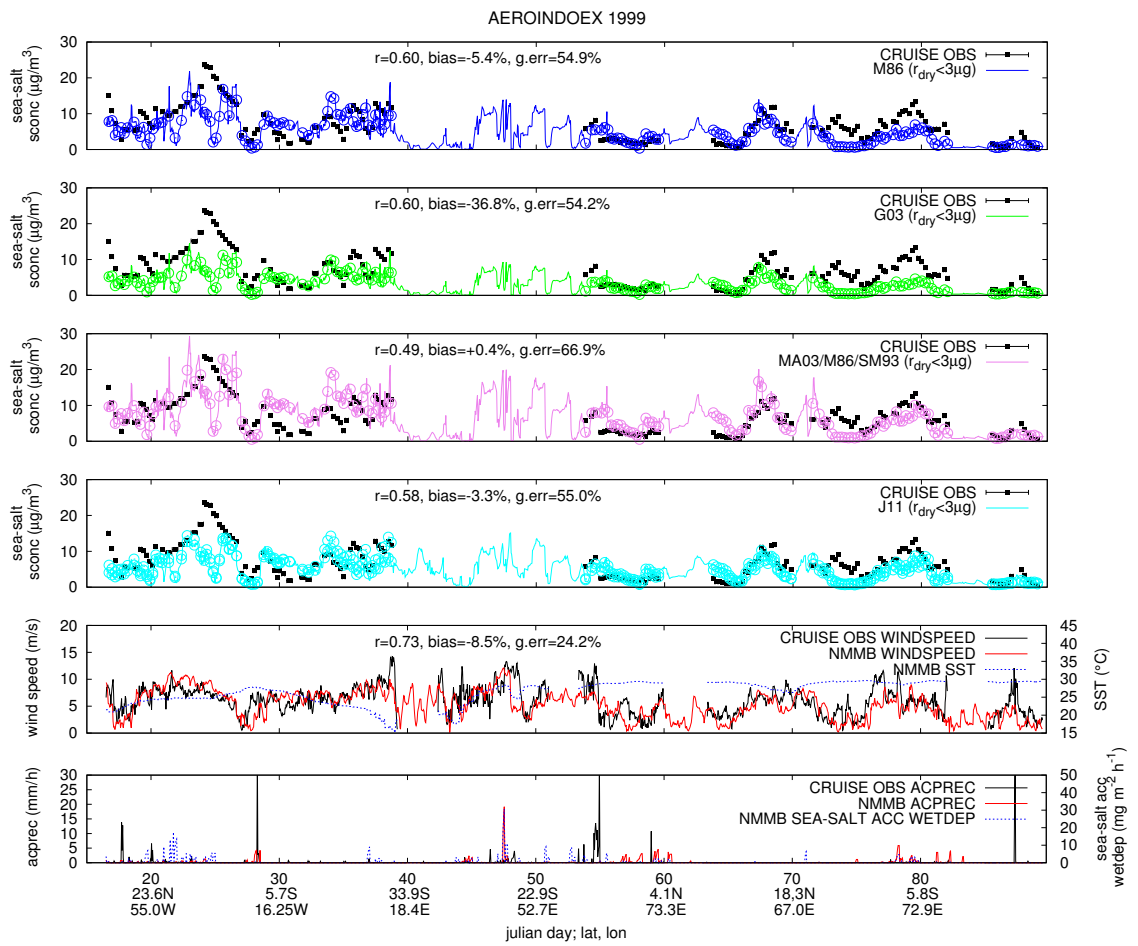

Fig. 6. From top to bottom: simulated sea-salt surface concentration (sconc) with M86 (blue), G03 (green), MA03/M86/SM93 (violet), and J11 (cyan) compared to AEROINDOEX cruise measurements (black squares), simulated wind speed (red line) compared to AEROINDOEX measurements (black line) (simulated SST is also shown), and simulated precipitation (red line) compared to AEROINDOEX measurements (black line) (simulated accumulated wet deposition is also shown). M86/SM93 is not shown since it is equivalent to M86 for $r_{\mathrm{d}}<3 \mu \mathrm{m}$. The model $1 \mathrm{~h}$-output surface concentrations are plotted with solid lines and averaged over the measurement times (circles). Skill scores shown are correlation $(r)$, mean normalized bias (bias), and mean normalized gross error (g.err.). 

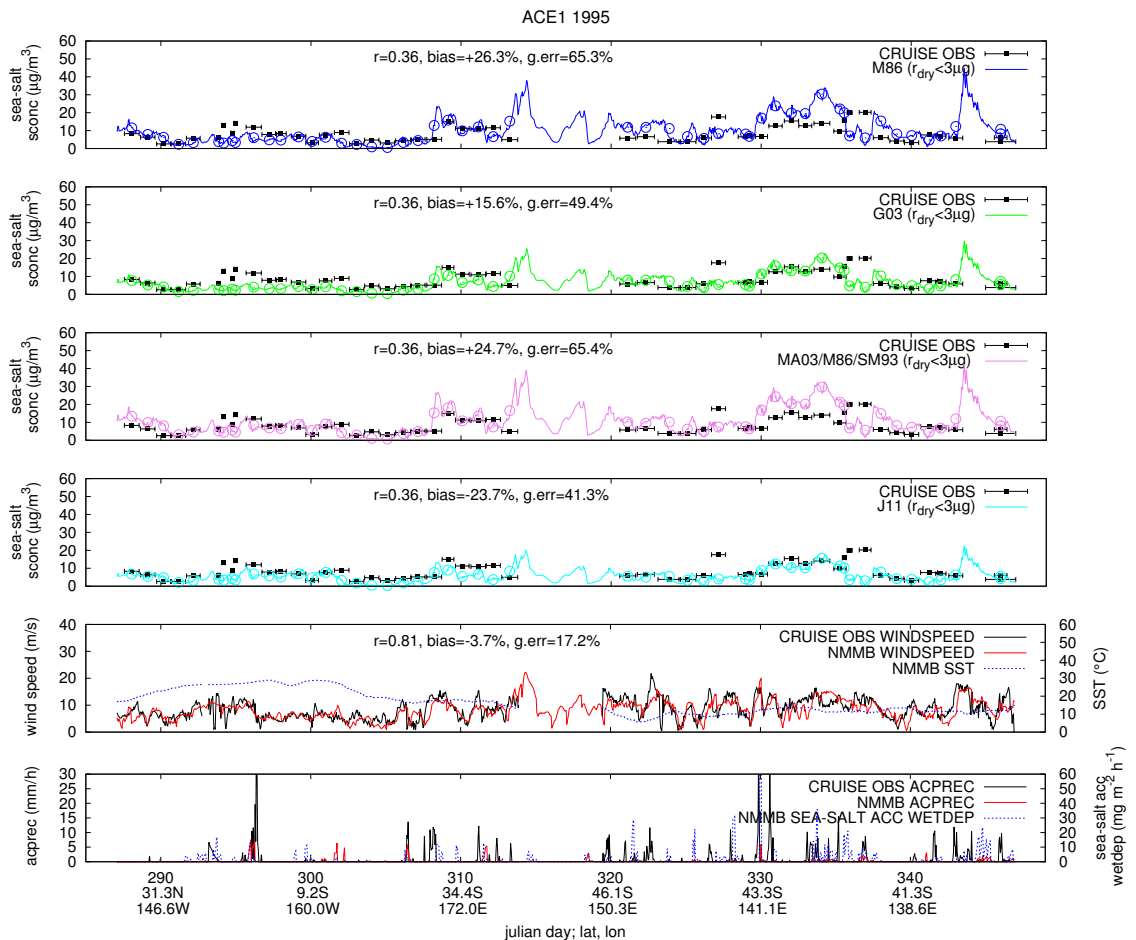

Fig. 7. From top to bottom: simulated sea-salt surface concentration (sconc) with M86 (blue), G03 (green), MA03/M86/SM93 (violet), and J11 (cyan) compared to ACE1 cruise measurements (black squares), simulated wind speed (red line) compared to ACE1 measurements (black line) (simulated SST is also shown), and simulated precipitation (red line) compared to ACE1 measurements (black line) (simulated accumulated wet deposition is also shown). M86/SM93 is not shown since it is equivalent to M86 for $r_{\mathrm{d}}<3 \mu \mathrm{m}$. The model $1 \mathrm{~h}-\mathrm{output}$ surface concentrations are plotted with solid lines and averaged over the measurement times (circles). Skill scores shown are correlation $(r)$, mean normalized bias (bias), and mean normalized gross error (g.err.).

and Witek et al. (2007) with GEOS-CHEM and NAAPS models, respectively. AEROINDOEX is simulated with a correlation close to 0.6 with M86, G03, and J11. The correlation decreases when employing the SST-dependent MA03/M86/SM93 (0.49). The mean normalized bias ranges from $+0.4 \%$ (MA03/M86/SM93) to $-36.8 \%$ (G03), showing an overall tendency of the model towards underestimation, mainly due to the misrepresentation of the peak around day 25 . The mean normalized gross error is around $60 \%$ for all cases.

For ACE1, the correlation is low (around 0.36) regardless of the emission scheme applied. The overall bias between model and observations ranges from $-23.7 \%$ (J11) to $26.3 \%$ (M86), with J11 being the only scheme with a negative bias. The gross error is around $50 \%$. Because of the larger measurement timescales of ACE1, part of the errors may be due to the inefficiency of the averaging technique.

Figures 6 and 7 also display the simulated wind speed (at $14 \mathrm{~m}$ and $33 \mathrm{~m}$ ), obtained by applying the power-law of Hsu et al. (1994) to $U_{10}$, observed wind speed, SST values, wet deposition and observed hourly precipitation. The measurements are $30 \mathrm{~min}$-averages and the model output is taken every $1 \mathrm{~h}$ as an instantaneous value for both cruises. Wind speed is simulated with a high correlation for AEROINDOEX (0.73) and ACE1 (0.81) and biases $(-8.5 \%$ and $-3.7 \%)$ and gross errors $(24.2 \%$ and $17.2 \%)$ are rather low.

The plotted SST values highlight the corrections introduced by the SST-dependent emissions (MA03/M86/SM93 and J11) on their parent schemes (M86/SM93 and G03, respectively). For example, the higher SST values taking place during the first 30 days of ACE1 produce a marked increase in concentration.

Simulated wet deposition peaks are generally in correspondence with peaks in observed precipitation, although the relative intensity may not always be well captured. Spurious precipitations and consequent wet deposition overestimation affect the concentration peak around day 25 of the AEROINDOEX campaign.

\subsection{Model surface concentration at U-MIAMI measurement sites}

Simulated surface concentration was compared with observed climatologies at 15 stations of the U-MIAMI network (Fig. 8). The discussion of the results is complemented by Fig. 9, where simulated wind speed is compared with a $30 \mathrm{yr}$ wind speed climatology (1981-2010) derived from the 

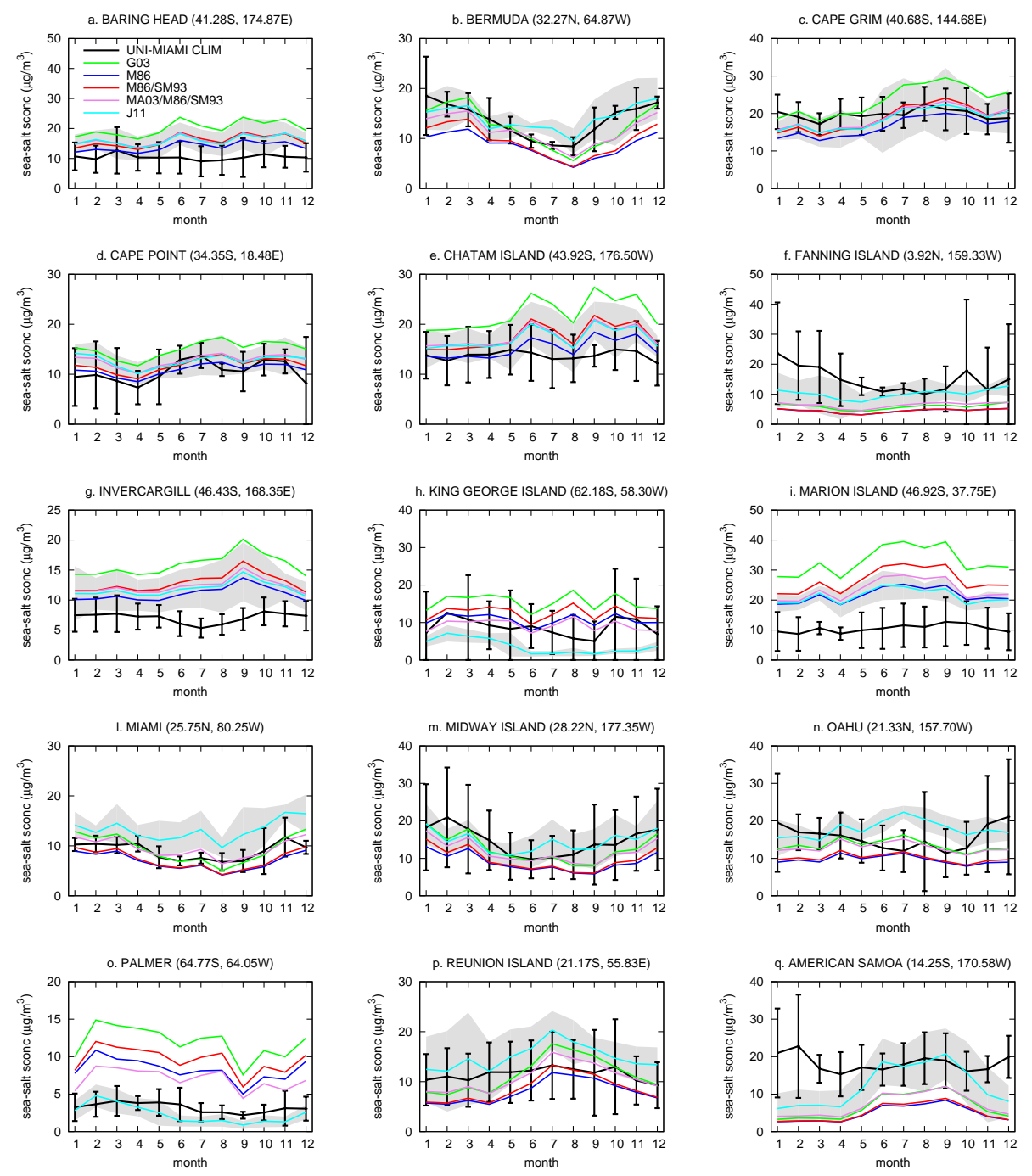

Fig. 8. Monthly mean simulated (color lines) and observed (black lines) sea-salt surface concentration at U-MIAMI stations. Simulated values cover a 5 yr period (2002-2006). U-MIAMI climatologies include interannual standard deviation bars. J11 interannual standard deviation is also shown (shaded grey). The label CLIM stands for climatologies.

NCEP/NCAR Reanalysis (Kalnay et al., 1996). We use this comparison in order to check the representativeness of our simulation temporal window (5 yr, 2002-2006) with respect to a more comprehensive model climatology.

Overall, simulated sea-salt concentrations are in good agreement with observations. Significant model overestimations of a factor of two or more are found in Invercargill (g), and Marion Island (i), where all schemes are above the observed mean plus one standard deviation. In these sites, overestimation cannot be attributed to an excess of wind speed compared with the NCEP/NCAR climatology (Fig. 9). A similar overestimation is found in Jaeglé et al. (2011) and Tsigaridis et al. (2013) in Marion Island (i) and in Invercargill (g) in Tsigaridis et al. (2013). Both studies use as well global models with an horizontal resolution greater than 1 degree. Since these sites are located in regions characterized by complex topography, we hypothesize that errors may be due in part to the low model resolution used.

In the Antarctic region, schemes show opposite performances in two stations close to each other. In Palmer (o), all schemes overestimate surface concentration with the exception of $\mathrm{J} 11$, which reproduces well the climatology. The overestimation of the wind speed with respect to the NCEP climatology does not entirely explain the behavior of M86, M86/SM93, G03, and MA03/M86/SM93. On the other hand, J11 leads to an underestimation of the observed climatology at King George Island (h) which cannot be attributed to wind speed. Contrasting results are found in this region when comparing our work with Jaeglé et al. (2011) and Tsigaridis et al. (2013).

Significant underestimation is found in Fanning Island (f) and American Samoa (q), both located in the tropical 

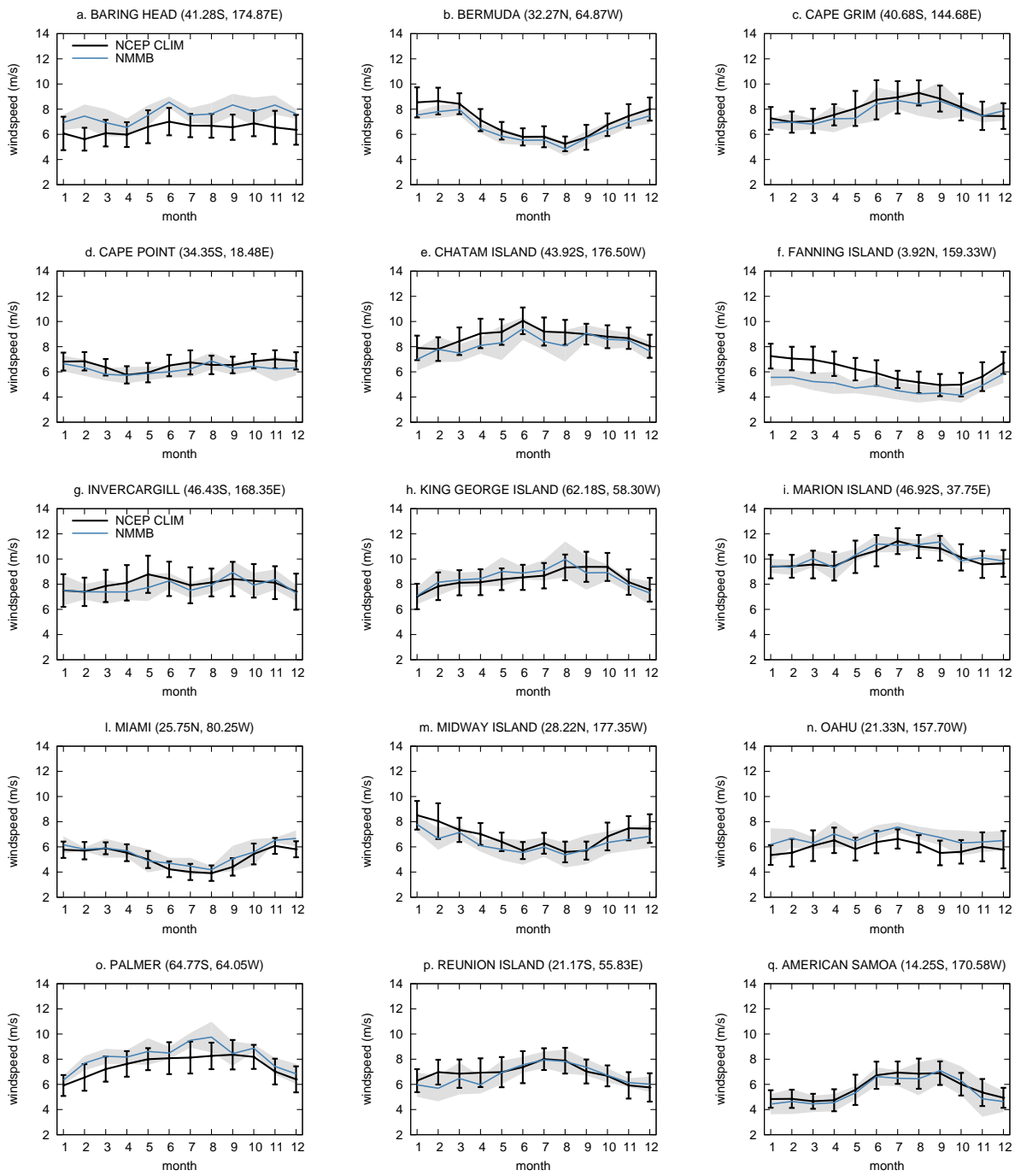

Fig. 9. Monthly mean simulated surface wind speed (2002-2006) (blue) and surface wind climatologies (1981-2010) from NCEP/NCAR Reanalysis (black) at U-MIAMI stations. Interannual standard deviations are shown for the simulation (shaded grey) and the NCEP/NCAR climatology (black bars).

Pacific. In Fanning Island (f), the low concentration could be associated to an underestimation of the wind speed, in contrast to American Samoa (q), where the simulated wind speed matches the NCEP climatology. Observed concentration climatologies present large standard deviations during boreal winter in these sites, which is inconsistent with the low variability of the simulated or climatological wind speed, suggesting a poor representativeness of the observed mean concentration. Significant underestimation of the U-MIAMI climatological values in Fanning Island (f) and American Samoa (q) is also found in Jaeglé et al. (2011) and Tsigaridis et al. (2013).

There is a significant influence of the applied emission scheme upon modeled sea-salt surface concentrations. Even the introduction of SST-dependence in MA03/M86/SM93, which only affects the smaller bins (from $0.1 \mu \mathrm{m}$ up to $1.4 \mu \mathrm{m}$ in dry radius), makes a relevant contribution to the simulated concentration. Fig. 10 includes scatterplots of observed and simulated values (neglecting Invercargill $(\mathrm{g}$ ) and Marion Island (i)) and a scatterplot of simulated wind speed and NCEP climatological values. Correlation, normalized bias, normalized gross error, and a linear regression fit are provided for each scatterplot. G03 generally overestimates the climatological monthly mean concentrations, while M86 underestimates. A significant reduction in bias is obtained when using M86/SM93 instead of M86. The best agreement is obtained with the SST-dependent emission schemes MA03/M86/SM93 and J11. Overestimation with G03 may be explained by its unclear description of spume particles production, as already noted in Fan and Toon (2011). Indeed, the emission flux for particles larger than $10 \mu \mathrm{m}$ in dry radius is nearly one order of magnitude larger than in the 

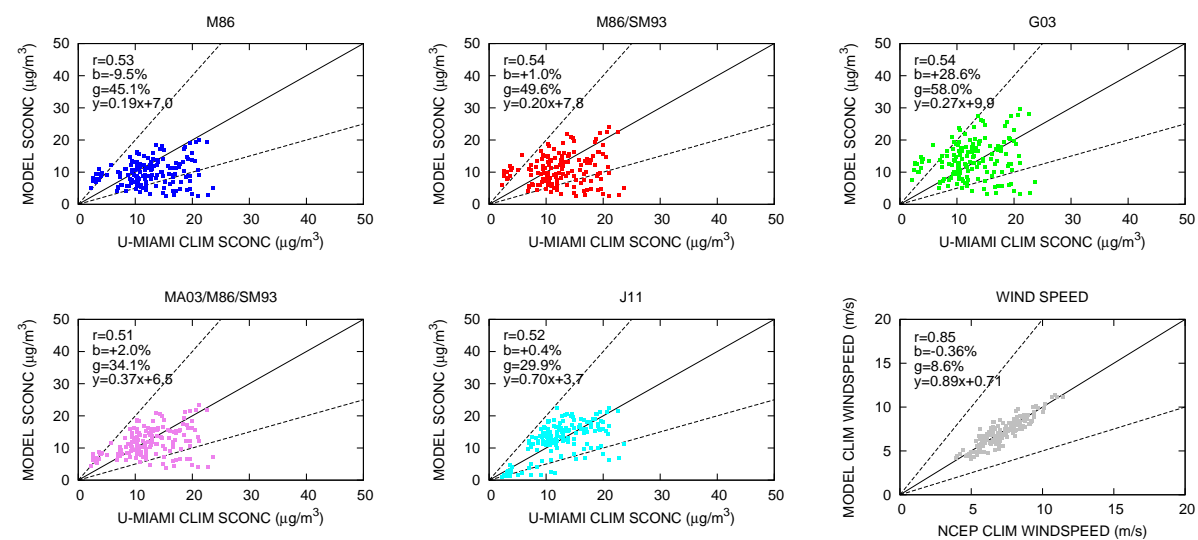

Fig. 10. Scatterplots of simulated surface monthly mean concentrations and climatologies from the U-MIAMI network for each emission scheme. Invercargill (g) and Marion Island (i) stations have been excluded. A scatterplot of simulated surface wind speed and NCEP/NCAR climatology is provided in the bottom-right panel. The plots are accompanied by $y=2^{ \pm 1} x$ dashed lines. $r, b$, and $g$ stand for overall mean correlation, normalized bias, and normalized gross error, respectively. A linear regression fit is also shown $(y=m x+q)$.

other implemented schemes (Fig. 1). On the other hand, the spume production is neglected in M86, which may partly explain the underestimated concentration. The introduction of spume particles in the combined M86/SM93 improves the model results. This improvement is more evident in stations and months characterized by frequent episodes of wind speed greater than $9 \mathrm{~m} \mathrm{~s}^{-1}$, such as for example during January, February and March in Bermuda (b) (Fig. 8). In the tropics, where these episodes are infrequent, M86 and M86/SM93 provide similar results.

The introduction of the SST-dependence in the emission scheme (both for MA03/M86/SM93 and J11) improves the overall statistics, with a reduction in bias and gross error (Fig. 10). The wind speed scatterplot suggests that biases could not be related to a weak representativeness of the simulated $5 \mathrm{yr}$ period.

\subsection{Aerosol optical depth}

Simulated coarse AOD are compared with monthly climatologies at 16 AERONET sites (Fig. 11). The model AOD is all-sky in contrast to AOD measurements, which are clearsky. The differences between all-sky and clear-sky results in models are currently uncertain and are thought to be moderate for sea-salt and very low for dust (Shindell et al., 2013).

To support the analysis, Fig. 12 displays the simulated wind speed and the NCEP wind speed climatology at each site. Overall, the simulated coarse AOD is in agreement with observations. Significant discrepancies are found in CeilapRG (6), Dunedin (9), Reunion Island (14), and Tahiti (16) with all schemes. Overestimation in Ceilap-RG (6) affects the entire seasonal cycle mostly due to errors in dust emissions from South America. Neglecting the dust contribution, the nearly constant seasonal cycle and its mean value $(\sim 0.02)$ are well reproduced. Overestimation in Bermuda (4), Dunedin (9), Reunion Island (14), and Tahiti (16) takes place mainly during austral winter (JJA). At Bermuda (4), Dunedin (9), and Tahiti (16) model peaks may be partly related to an overestimated wind speed (Fig. 12).

Both at Reunion Island (14) and Dunedin (9) the significant dust contribution leads to uncertainties in the comparison. At Ascension Island (2), Bermuda (4), Cape San Juan (5), La Parguera (11), and Midway Island (12), the model's ability to reproduce the dust cycle is decisive for a proper simulation of the coarse AOD.

Results outline a close behavior among G03, M86 and M86/SM93, in contrast to SST-dependent schemes (MA03/M86/SM93 and J11). The latter tend to overestimate the AOD over warm sea surfaces in/near the tropics (e.g. Bermuda (4), Coconut Island (7), Guam Island (10), Midway Island (12), Reunion Island (14), and Tahiti (16)). These results are mainly related to differences in the emitted size-distribution and the hygroscopic growth of sub-micron aerosols affecting the coarse AOD. Figure 1 shows close to an order of magnitude difference in the number emission flux for particles with dry radius in the range $0.15-1.4 \mu \mathrm{m}$. Hygroscopic growth of particles above $0.6 \mu \mathrm{m}$ adds up to explain the higher coarse AOD when using an SST-dependent scheme. Simulated wind speeds are stronger than NCEP climatological winds in Coconut Island (7), Guam Island (10), and Tahiti (16) (Fig. 12), which may also partly explain the overestimation in these sites. On the contrary, in Bermuda (4), Midway Island (12), and Reunion Island (14) the simulated wind speed is lower than the NCEP climatology.

In the subset of stations in/near the tropics, Jaeglé et al. (2011) found that their model generally underestimates the observed climatologies and the introduction of a SST-dependent term leads to an improvement of their model performance. In our work, we also find an increase in AOD at low latitudes when applying SST-dependent 

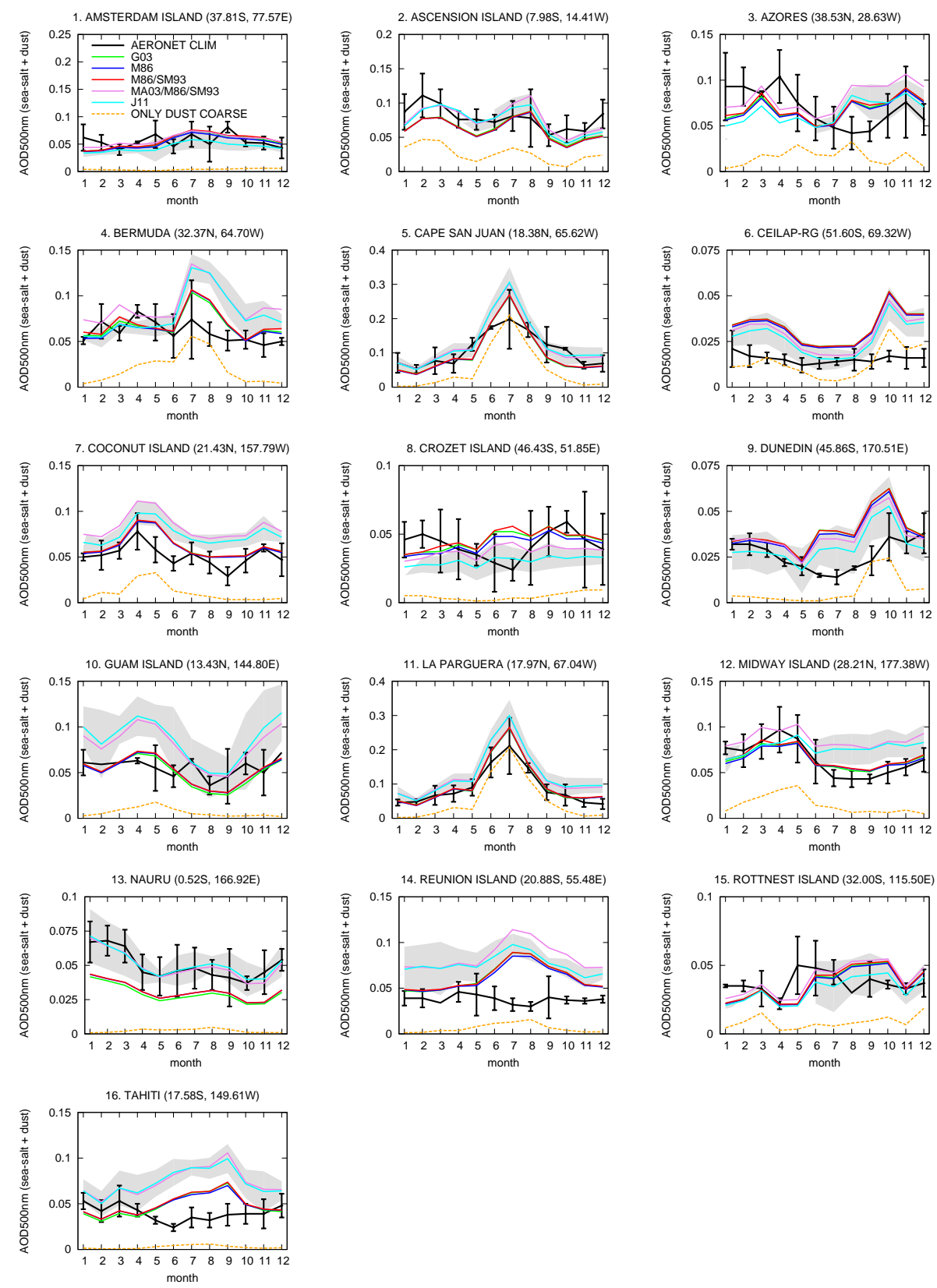

Fig. 11. Monthly mean simulated sea salt + dust coarse AOD at $500 \mathrm{~nm}$ (color lines) and observed coarse AOD at $500 \mathrm{~nm}$ (black lines) at selected AERONET stations. Simulated values refer to averages over the simulated $5 \mathrm{yr}$ period (2002-2006). AERONET climatologies include interannual standard deviation bars. J11 interannual standard deviation is also shown (shaded grey). The dust contribution is highlighted with the orange line. The label COARSE stands for coarse fraction of AOD; the label CLIM stands for climatologies.

emission schemes, although it produces an overestimation of AERONET climatologies.

Figure 13 displays scatterplots of simulated and observed coarse AOD, excluding Ceilap-RG (6) due to the significant errors in the dust component. MA03/M86/SM93 and J11 produce the largest positive biases $(+38.8 \%$ and $+27.5 \%$, respectively) and gross errors (above $40 \%$ ). The wind speed scatterplot indicates that such overestimation cannot be explained by a wind speed overestimation.

\section{Conclusions}

We presented simulations of the sea-salt aerosol global distribution with the multiscale model NMMB/BSC-CTM. Since the main uncertainties in sea-salt modeling are related to the parameterization of emissions, we implemented five different sea-salt emission schemes and analyzed their performance. We compared global simulations covering the period 2002-2006 with climatologies from the U-MIAMI and 

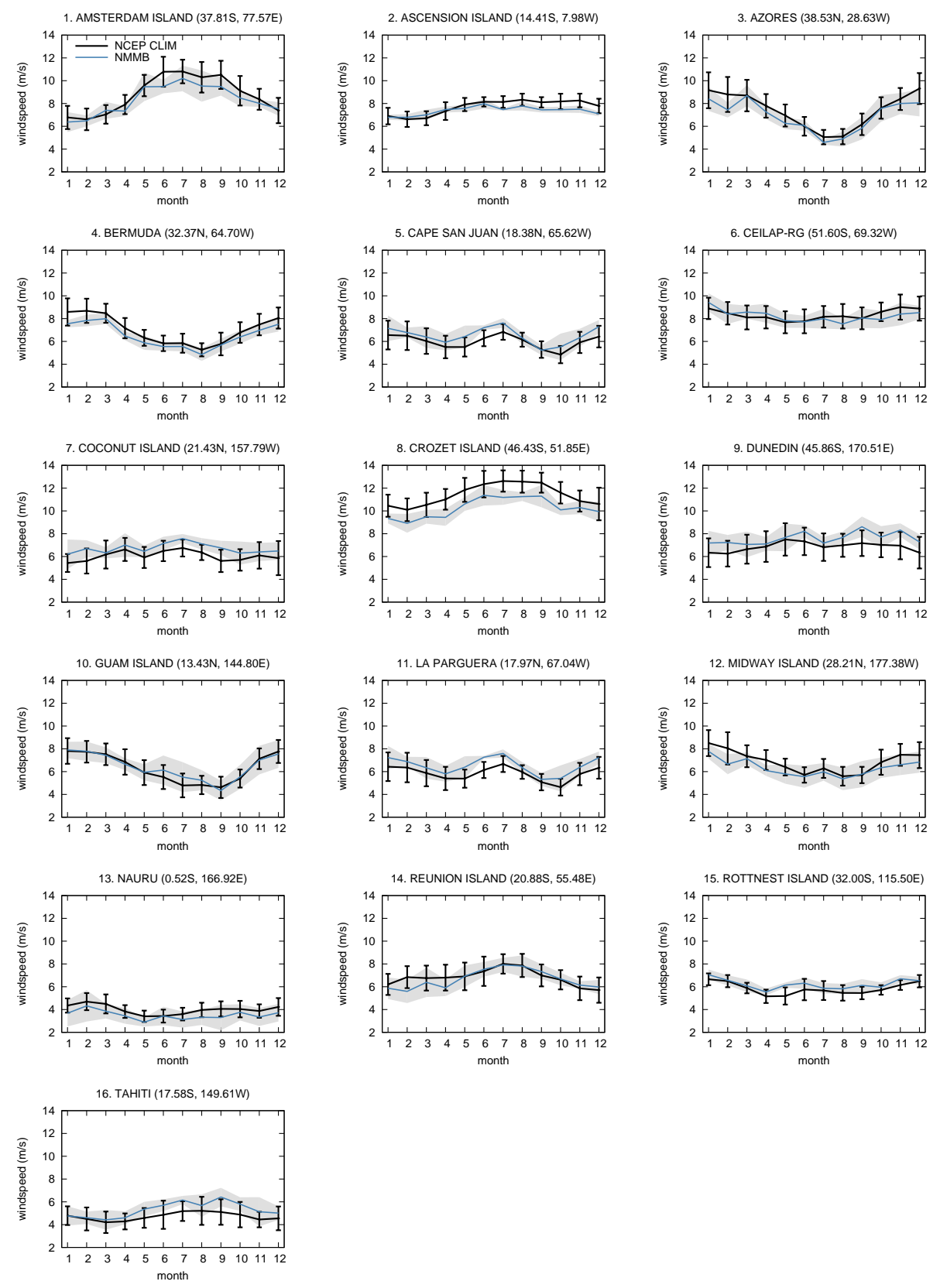

Fig. 12. Monthly mean simulated surface wind speed (2002-2006) (blue) and surface wind climatologies (1981-2010) from NCEP/NCAR Reanalysis (black) at selected AERONET stations. Interannual standard deviations are shown for the simulation (shaded grey) and the NCEP/NCAR climatology (black bars).

"sea-salt-dominated" stations from the AERONET sun photometer network. For the comparison with AERONET, we use the coarse fraction of the AOD.

We found a strong sensitivity of sea-salt aerosol lifetime to the emission scheme, ranging from $7.3 \mathrm{~h}$ to $11.3 \mathrm{~h}$. The use of SST-dependent emission schemes produces an enhancement of the sea-salt lifetime, which increases from $7.3 \mathrm{~h}$ with $\mathrm{G} 03$ to $9.6 \mathrm{~h}$ with $\mathrm{J} 11$ and from $8.9 \mathrm{~h}$ with M86/SM93 to $10.4 \mathrm{~h}$ with MA03/M86/SM93.
The SST latitudinal modulation with J11 and MA03/M86/SM93 also leads to marked differences in the global patterns of surface concentration and AOD compared with M86, M86/SM93, and G03. In particular, maximum AOD values are reached at high latitudes with M86, M86/SM93, and G03, and in the tropics with J11 and MA03/M86/SM93.

SST-dependent emission schemes lead to a clear improvement of the simulated surface concentration, with a 

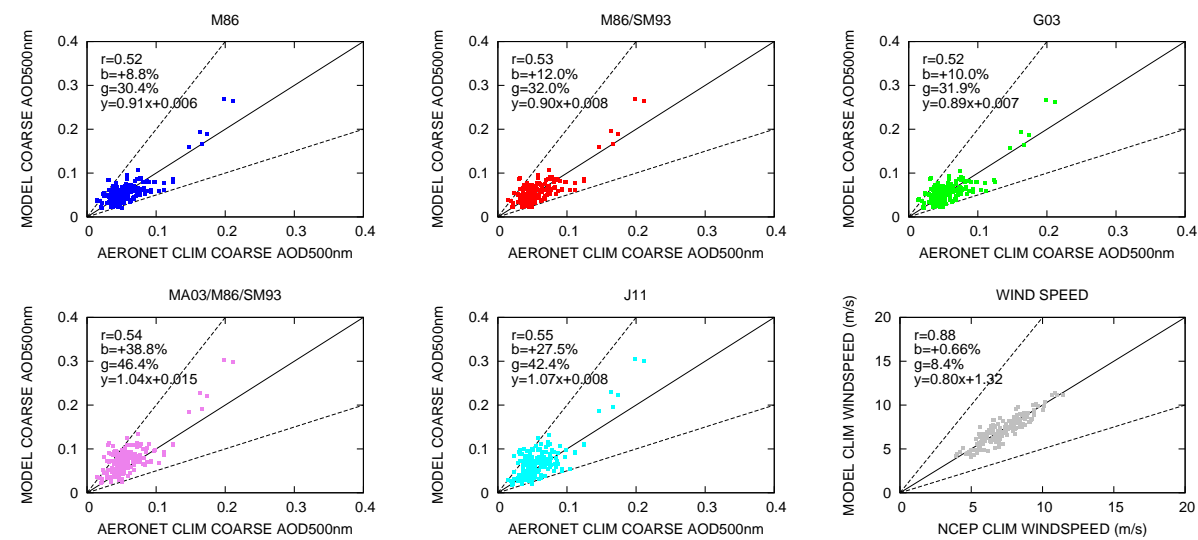

Fig. 13. Scatterplots of simulated sea-salt+dust coarse AOD at $500 \mathrm{~nm}$ and climatologies from the AERONET network for each emission scheme. Ceilap-RG (6) has been excluded, since the dust errors affecting its region. A scatterplot of simulated surface wind speed and NCEP/NCAR climatology is provided in the bottom-right panel. The plots are accompanied by $y=2^{ \pm 1} x$ dashed lines. $r, b$, and $g$ stand for overall mean correlation, normalized bias, and normalized gross error, respectively. A linear regression fit is also shown $(y=m x+q)$.

significant reduction of bias and gross error. In particular, J11 shows the best agreement with observations. However, the simulated coarse AOD with $\mathrm{J} 11$ and MA03/M86/SM93 is affected by positive biases at several AERONET sites located in the tropics. Factors that may explain the AOD overestimation include the use of all-sky model AOD in the comparison and the treatment of the water uptake, deposition, and optical properties in the model. Further research may aim at investigating SST effects upon particle size distribution.

As in previous studies, the model shows a strong overestimation in sites characterized by steep topography (Invercargill (g) in New Zealand and Marion Island (i)), independently from the applied emission scheme. Our preliminary results with a high-resolution regional simulation suggest that smaller scales play a key role in these sites. A detailed investigation at these sites is underway.

The development of the sea-salt module of the NMMB/BSC-CTM is a step forward towards an aerosol model, including dust (Pérez et al., 2011), black and organic carbon, sulfate, and its online coupling with the gas-phase chemistry (Jorba et al., 2012) to obtain a unified online multiscale chemical weather forecasting system.

Acknowledgements. We would like to thank the scientists of the AERONET Program, the University of Miami Ocean Aerosol Network, the NOAA/PMEL Laboratory, and the AEROCOM Project for establishing and providing data from the stations/cruises/models used in this work. In particular, we thank J. Prospero for his personal communications and M. Schulz for providing postprocessing of the University of Miami Ocean Aerosol Network data set. We also thank F. Benincasa for technical support. BSC acknowledges the support from projects CGL2010/19652, "Supercomputación and e-ciencia" Project (CSD2007-0050) from the ConsoliderIngenio 2010 program of the Spanish Ministry of Economy and Competitiveness and the support from the grant SEV-2011-00067 of Severo Ochoa Program, awarded by the Spanish Government.
Simulations were performed in the Marenostrum Supercomputer at BSC. The two Anonymous Reviewers are gratefully acknowledged for their detailed and helpful comments.

Edited by: A. Pszenn

\section{References}

Andreas, E. L.: A new sea spray generation functions for wind speeds up to $32 \mathrm{~m} \mathrm{~s}^{-1}$, J. Phys. Oceanogr., 28, 2175-2184, 1998.

Betts, A. K.: A new convective adjustment scheme, Part I: Observational and theoretical basis., Q. J. Roy. Meteor. Soc., 112, 677691, 1986.

Betts, A. K., and Miller, M. J.: A new convective adjustment scheme, Part II: Single column tests using GATE wave, BOMEX, ATEX and Artic air-mass data sets, Q. J. Roy. Meteor. Soc., 112, 693-709, 1986.

Caffrey, P. F., Hoppel, W. A., and Shi, J. J.: A one-dimensional sectional aerosol model integrated with mesoscale meteorological data to study marine boundary layer aerosol dynamics, J. Geophys. Res., 111, D24201, doi:10.1029/2006JD007237, 2006.

Chin, M., Ginoux, P., Kinne, S., Torres, O., Holben, B. N., Duncan, B. N., Martin, R. V., Logan, J. A., Higurashi, A., and Nakajima, T.: Tropospheric aerosol optical thickness from the GOCART model and comparisons with satellite and sun photometer measurements, J. Atmos. Sci., 59, 461-483, 2002.

Clarke, A. D., Owens, S. R., and Zhou, J.: An ultrafine sea-salt flux from breaking waves: implications for cloud condensation nuclei in the remote marine atmosphere, J. Geophys. Res., 111, D06202, doi:10.1029/2005JD006565, 2006.

d'Almeida, G. A.: Atmospheric Aerosolsx, Deepak Publishing, Hampton, Virginia, 561 pp., 1991.

de Leeuw, G., Neele, F. P., Hill, M., Smith, M. H., and Vignati, E.: Production of sea spray aerosol in the surf zone, J. Geophys. Res., 105, 29397-29409, 2000.

de Leeuw, G., Andreas, E. L., Anguelova, M. D., Fairall, C. W., Lewis, E. R., O’Dowd, C., Schulz, M., and Schwartz, S. E.: Pro- 
duction flux of sea spray aerosol, Rev. Geophys, 49, RG2001, doi:10.1029/2010RG000349, 2011.

Fan, T. and Toon, O. B.: Modeling sea-salt aerosol in a coupled climate and sectional microphysical model: mass, optical depth and number concentration, Atmos. Chem. Phys., 11, 4587-4610, doi:10.5194/acp-11-4587-2011, 2011.

Fels, S. B. and Schwarzkopf, M. D.: The simplified exchange approximation: a new method for radiative transfer calculations, J. Atmos. Sci., 32, 1475-1488, 1975.

Ferrier, B. S., Jin, Y., Lin, Y., Black, T., Rogers, E., and DiMego, G.: Implementation of a new frid-scale cloud and precipitation shceme in the NCEP Eta Model, in: Proc. 15th Conf. on Numerical Weather Prediction, San Antonio, 12-16 August 2002, TX, American Meteorological Society, 280-283, 2002.

Gerber, H.: Relative-humidity parameterization of the navy aerosol model (NAM), Tech. rep., Tech. Rep. 8956, National Research Laboratory, Washington DC, 1985.

Ghan, S. J., Laulainen, N., Easter, R. C., Wagener, R., Nemesure, S., Chapman, E., and Leung, Y. Z. R.: Evaluation of aerosol direct radiative forcing in MIRAGE, J. Geophys. Res., 106, 5295-5316, 2001.

Grythe, H., Ström, J., Krejci, R., Quinn, P., and Stohl, A.: A review of sea spray aerosol source functions using a large global set of sea salt aerosol concentration measurements, Atmos. Chem. Phys. Discuss., 13, 20729-20781, doi:10.5194/acpd-13-207292013, 2013.

Gong, S. L.: A parameterization of sea-salt aerosol source function for sub and super-micron particles, Global Biogeochem. Cy., 17, 1097, doi:10.1029/2003GB002079, 2003.

Haustein, K., Pérez, C., Baldasano, J. M., Jorba, O., Basart, S., Miller, R. L., Janjic, Z., Black, T., Nickovic, S., Todd, M. C., Washington, R., Müller, D., Tesche, M., Weinzierl, B., Esselborn, M., and Schladitz, A.: Atmospheric dust modeling from meso to global scales with the online NMMB/BSC-Dust model - Part 2: Experimental campaigns in Northern Africa, Atmos. Chem. Phys., 12, 2933-2958, doi:10.5194/acp-12-2933-2012, 2012.

Holben, B. N., Eck, T. F., Slutsker, I., Tanré, D., Buis, J. P., Setzer, A., Vermote, E., Reagan, J. A., Kaufman, Y., Nakajima, T., Lavenu, F., Jankowiak, I., and Smirnov, A.: AERONET - a federated instrument network and data archive for aerosol characterization, Remote Sens. Environ., 66, 1-16, 1998.

Hoppel, W. A., Frick, G. M., and Fitzgerald, J. W.: Surface source function for sea-salt aerosol and aerosol dry deposition to the ocean surface, J. Geophys. Res., 107, 4382, doi:10.1029/2001JD002014, 2002.

Hsu, S. A., Meindl, E. A., and Gilhousen, D. B.: Determining the power law wind-profile exponent under near-neutral stability conditions at sea, Appl. Meteorol., 33, 757-765, doi:10.1175/1520-0450(1994)033<0757:DTPLWP>2.0.CO;2, 1994.

Jaeglé, L., Quinn, P. K., Bates, T. S., Alexander, B., and Lin, J.-T.: Global distribution of sea salt aerosols: new constraints from in situ and remote sensing observations, Atmos. Chem. Phys., 11, 3137-3157, doi:10.5194/acp-11-3137-2011, 2011.

Janjic, Z. I.: Pressure gradient force and advection scheme used for forecasting with steep and small scale topography, Contributes to Atmospheric Physics, 150, 186-199, 1977.
Janjic, Z. I.: Forward-backward scheme modified to prevent twogrid interval noise and its application in sigma coordinate models, Contributes to Atmospheric Physics, 52, 69-84, 1979.

Janjic, Z. I.: Non-linear advection schemes and energy cascade on semi-staggered grids, Mon. Weather Rev., 112, 1234-1245, 1984.

Janjic, Z. I.: The step-mountain eta coordinate model: physical package, Mon. Weather Rev., 118, 1429-1443, 1990.

Janjic, Z. I.: The step-mountain eta coordinate model: further developments of the convection, viscous sublayer, and turbulence closure schemes, Mon. Weather Rev., 122, 927-945, 1994.

Janjic, Z. I.: The surface layer in the NCEP eta model, 11th Conference on Numerical Weather Prediction, Norfolk, VA, 19-23 August 1996; American Meteorological Society, Boston, MA, 354-355, 1996.

Janjic, Z. I.: Comments on "Development and evaluation of a convection scheme for use in climate models", J. Atmos. Sci., 57, 3686-3686, doi:10.1175/1520 0469(2000)057<3686:CODAEO>2.0.CO;2, 2000.

Janjic, Z. I.: Nonsingular implementation of the MellorYamada Level 2.5 Scheme in the NCEP Meso model, Tech. rep., NOAA/NWS/NCEP Office Note No. 436, 61 pp., avalaible at: http://www.emc.ncep.noaa.gov/officenotes/ newernotes/on437.pdf (last access: December 2012), 2001.

Janjic, Z. I.: A nonhydrostatic model based on a new approach, Meteorol. Atmos. Phys., 82, 271-285, doi:10.1007/s00703-0010587-6, 2003.

Janjic, Z. I.: A unified model approach from meso to global scales, Geophys. Res. Abs., 7, SRef-ID: 1607-7962/gra/EGU05-A-05 582, 2005.

Janjic, Z. I. and Black, T.: A unified model approach from meso to global scales, Geophys, Res, Abs,, 7, SRef-ID: 16077962/gra/EGU2007-A-05 025, 2007.

Janjic, Z.: Further development of the unified multiscale Eulerian model for a broad range of spatial and temporal scales within the new National Environmental Modeling System, EGU General Assembly 2009, held 19-24 April 2009, Wien, Austria, abstract EGU2009-1587, 11, 1587 pp., 2009.

Janjic, Z. I. and Gall, R.: Scientific documentation of the NCEP nonhydrostatic multiscale model on the $B$ grid (NMMB), Part 1 Dynamics, Tech. rep., NCAR/TN-489+STR, doi:10.5065/D6WH2MZX, availabe at: http://nldr.library.ucar. edu/repository/collections/TECH-NOTE-000-000-000-857 (last access: December 2012), 2012.

Janjic, Z. I., Gerrity, J. P., and Nickovic, S.: An alternative approach to nonhydrostatic modeling, Mon. Weather Rev., 129, 1164-1178, doi:10.1175/15200493(2001)129<1164:AAATNM>2.0.CO;2, 2001.

Janjic, Z. I., Janjic, T., and Vasic, R.: A class of conservative fourth order advection schemes and impact of enhanced formal accuracy on extended range forecasts, Mon. Weather Rev., 139, 15561568, doi:10.1175/2010MWR3448.1, 2011.

Jorba, O., Dabdub, D., Blaszczak-Boxe, C., Pérez, C., Janjic, Z., Baldasano, J. M., Spada, M., Badia, A., and Gonçalves, M.: Potential significance of photoexcited $\mathrm{NO}_{2}$ on global air quality with the NMMB/BSC chemical transport model, J. Geophys. Res., 117, D13301, doi:10.1029/2012JD017730, 2012.

Kalnay, E., Kanamitsu, M., Kistler, R., Collins, W., Deaven, D., Gandin, L., Iredell, M., Saha, S., White, G., Woollen, J., Zhu, 
Y., Chelliah, M., Ebisuzaki, W., Higgins, W., Janowiak, J., Mo, K. C., Ropelewski, C., Wang, J., Leetmaa, A., Reynolds, R., Jenne, R., and Joseph, D.: The NCEP/NCAR 40-year reanalysis project, B. Am. Meteorol. Soc., 77, 437-470, doi:10.1175/15200477(1996)077\%3C0437:TNYRP\%3E2.0.CO;2, 1996.

Köepke, P., Hess, M., Schult, I., and Shettle, E. P.: Global aerosol dataset, report, Tech. rep., Max-Planck Institute für Meteorologie, Hamburg, Germany, 1997.

Lacis, A. A. and Hansen, J. E.: A parameterization for the absorption of solar radiation in the Earth's atmosphere, J. Atmos. Sci., 31, 118-133, 1974.

Lewis, E. R. and Schwartz, S. E.: Sea Salt Aerosol Production: Mechanisms, Methods, Measurements, and Models, American Geophysical Union, Washington DC, 9-13, 2004.

Mårtensson, E. M., Nilsson, E. D., de Leeuw, G., Cohen, L. H., and Hansson, H.-C.: Laboratory simulations and parameterization of the primary marine aerosol production, J. Geophys. Res., 108, 4297, doi:10.1029/2002JD002263, 2003.

Mellor, G. L. and Yamada, T.: Development of a turbulence closure model for geophysical fluid problems, Rev. Geophys. Space Phys., 20, 851-875, 1982.

Mishchenko, M. I., Travis, L. D., and Lacis, A. A.: Scattering, Absorption, and Emission of Light by Small Particles, Cambridge University Press, Cambridge, 2002.

Mlawer, E. J., Taubman, S. J., Brown, P. D., Iacono, M. J., and Clough, S. A.: Radiative transfer for inhomogeneous atmosphere: RRTM, a validated correlated-k model for the longwave, J. Geophys. Res., 102, 16663-16682, 1997.

Monahan, E. C., Spiel, D. E., and Davidson, K. L.: A model of marine aerosol generation via whitecaps and wave disruption, in: Oceanic Whitecaps, edited by: Monahan, E. C. and Mac Niocaill, G., 167-174, D. Reidel, Norwell, Massachusetts, 1986.

Monin, A. S. and Obukhov, A. M.: Basic laws of turbulent mixing in the surface layer of the atmosphere, Contrib. Geophys. Inst. Acad. Sci. USSR, 151, 163-187, 1954 (in Russian).

O'Dowd, C. D. and de Leeuw, G.: Marine aerosol production: a review of the current knowledge, Philos. T. Roy. Soc. A, 365, 1753-1774, doi:10.1098/rsta.2007.2043, 2007.

Pérez, C., Haustein, K., Janjic, Z., Jorba, O., Huneeus, N., Baldasano, J. M., Black, T., Basart, S., Nickovic, S., Miller, R. L., Perlwitz, J. P., Schulz, M., and Thomson, M.: Atmospheric dust modeling from meso to global scales with the online NMMB/BSC-Dust model - Part 1: Model description, annual simulations and evaluation, Atmos. Chem. Phys., 11, 1300113027, doi:10.5194/acp-11-13001-2011, 2011.

Petelski, T., Piskozub, J., and Paplinska-Swerpel, B.: Sea spray emission from the surface of the open Baltic Sea, J. Geophys. Res., 110, C10023, doi:10.1029/2004JC002800, 2005.

Quinn, P. K. and Bates, T. S.: Regional aerosol properties: Comparisons of boundary layer measurements from ACE1, ACE2, aerosols99, INDOEX, ACE asia, TARFOX, and NEAQS, J. Geophys. Res., 110, D14202, doi:10.1029/2004JD004755, 2005.

Quinn, P. K., Coffman, D. J., Kapustin, V. N., Bates, T. S., and Covert, D. S.: Aerosol optical properties in the marine boundary layer during the First Aerosol Characterization Experiment (ACE1) and the underlying chemical and physical aerosol properties, J. Geophys. Res., 103, 16547-16563, 1998.
Reid, J. S., Jonsson, H. H., Smith, M. H., and Smirnov, A.: Evolution of the vertical profile and flux of large sea-salt particles in a coastal zone, J. Geophys. Res., 34, 12039-12053, 2001.

Sandwell, D. T. and Agreen, R. W.: Seasonal variation in wind speed and sea state from global satellite measurements, J. Geophys. Res., 89, 2041-2051, 1984.

Savoie, D. L. and Prospero, J. M.: Aerosol concentration statistics for the Northern Tropical Atlantic, J. Geophys. Res., 82, 59545964, doi:10.1029/JC082i037p05954, 1977.

Shindell, D. T., Lamarque, J.-F., Schulz, M., Flanner, M., Jiao, C., Chin, M., Young, P. J., Lee, Y. H., Rotstayn, L., Mahowald, N., Milly, G., Faluvegi, G., Balkanski, Y., Collins, W. J., Conley, A. J., Dalsoren, S., Easter, R., Ghan, S., Horowitz, L., Liu, X., Myhre, G., Nagashima, T., Naik, V., Rumbold, S. T., Skeie, R., Sudo, K., Szopa, S., Takemura, T., Voulgarakis, A., Yoon, J.-H., and Lo, F.: Radiative forcing in the ACCMIP historical and future climate simulations, Atmos. Chem. Phys., 13, 2939-2974, doi:10.5194/acp-13-2939-2013, 2013.

Simmons, A. J. and Burridge, D. M.: An energy and angular momentum conserving vertical finite-difference scheme and hybrid vertical coordinates, Mon. Weather Rev., 109, 758-766, 1981.

Slinn, W. G. N.: Predictions for particle deposition to vegetative canopies, Atmos. Environ., 16, 1785-1794, 1982.

Slinn, W. G. N.: Precipitation scavenging, in: Atmospheric Science and Power Production, edited by: Randerson, D., 466-532, OSTI, Oak Ridge, 1984.

Smirnov, A., Holben, B. N., Eck, T. F., Dubovik, O., and Slutsker, I.: Cloud screening and quality control algorithms for the AERONET data-base, Remote Sens. Environ., 73, 337-349, doi:10.1016/S0034-4257(00)00109-7, 2000.

Smirnov, A., Holben, B. N., Giles, D. M., Slutsker, I., O’Neill, N. T., Eck, T. F., Macke, A., Croot, P., Courcoux, Y., Sakerin, S. M., Smyth, T. J., Zielinski, T., Zibordi, G., Goes, J. I., Harvey, M. J., Quinn, P. K., Nelson, N. B., Radionov, V. F., Duarte, C. M., Losno, R., Sciare, J., Voss, K. J., Kinne, S., Nalli, N. R., Joseph, E., Krishna Moorthy, K., Covert, D. S., Gulev, S. K., Milinevsky, G., Larouche, P., Belanger, S., Horne, E., Chin, M., Remer, L. A., Kahn, R. A., Reid, J. S., Schulz, M., Heald, C. L., Zhang, J., Lapina, K., Kleidman, R. G., Griesfeller, J., Gaitley, B. J., Tan, Q., and Diehl, T. L.: Maritime aerosol network as a component of AERONET - first results and comparison with global aerosol models and satellite retrievals, Atmos. Meas. Tech., 4, 583-597, doi:10.5194/amt-4-583-2011, 2011.

Smith, M. H. and Harrison, N. M.: The sea spray generation function, J. Atmos. Sci., 29, 189-190, 1998.

Smith, M. H., Park, P. M., and Consterdine, I. E.: Marine aerosol concentrations and estimated fluxes over the sea, Q. J. Roy. Meteor. Soc., 809-824, 1993.

Textor, C., Schulz, M., Guibert, S., Kinne, S., Balkanski, Y., Bauer, S., Berntsen, T., Berglen, T., Boucher, O., Chin, M., Dentener, F., Diehl, T., Easter, R., Feichter, H., Fillmore, D., Ghan, S., Ginoux, P., Gong, S., Grini, A., Hendricks, J., Horowitz, L., Huang, P., Isaksen, I., Iversen, I., Kloster, S., Koch, D., Kirkevåg, A., Kristjansson, J. E., Krol, M., Lauer, A., Lamarque, J. F., Liu, X., Montanaro, V., Myhre, G., Penner, J., Pitari, G., Reddy, S., Seland, $\varnothing .$, Stier, P., Takemura, T., and Tie, X.: Analysis and quantification of the diversities of aerosol life cycles within AeroCom, Atmos. Chem. Phys., 6, 1777-1813, doi:10.5194/acp-6-1777-2006, 2006. 
Textor, C., Schulz, M., Guibert, S., Kinne, S., Balkanski, Y., Bauer, S., Berntsen, T., Berglen, T., Boucher, O., Chin, M., Dentener, F., Diehl, T., Feichter, J., Fillmore, D., Ginoux, P., Gong, S., Grini, A., Hendricks, J., Horowitz, L., Huang, P., Isaksen, I. S. A., Iversen, T., Kloster, S., Koch, D., Kirkevåg, A., Kristjansson, J. E., Krol, M., Lauer, A., Lamarque, J. F., Liu, X., Montanaro, V., Myhre, G., Penner, J. E., Pitari, G., Reddy, M. S., Seland, Ø., Stier, P., Takemura, T., and Tie, X.: The effect of harmonized emissions on aerosol properties in global models an AeroCom experiment, Atmos. Chem. Phys., 7, 4489-4501, doi:10.5194/acp-7-4489-2007, 2007.

Tsigaridis, K., Koch, D., and Menon, S.: Uncertainties and importance of sea spray composition on aerosol direct and indirect effects, J. Geophys. Res., 118, 220-235, doi:10.1029/2012JD018165, 2013.

Tsyro, S., Aas, W., Soares, J., Sofiev, M., Berge, H., and Spindler, G.: Modelling of sea salt concentrations over Europe: key uncertainties and comparison with observations, Atmos. Chem. Phys., 11, 10367-10388, doi:10.5194/acp-11-10367-2011, 2011.

Vignati, E., Wilson, J., and Stier, P.: M7: a size resolved aerosol mixture module for the use in global aerosol models, J. Geophys. Res., 109, D22202, doi:10.1029/2003JD004485, 2004.
Witek, M. L., Flatau, P. J., Quinn, P. K., and Westphal, D. L.: Global sea-salt modeling: results and validation against multicampaign shipboard measurements, J. Geophys. Res., 112, D08215, doi:10.1029/2006JD007779, 2007.

Witek, M. L., Flatau, P. J., Teixeira, J., and Markowicz, K. M.: Numerical investigation of sea salt aerosol size bin partitioning in global transport models: implications for mass budget and optical depth, Aerosol Sci. Tech., 45, 401-414, doi:10.1080/02786826.2010.541957, 2011.

Zakey, A. S., Solmon, F., and Giorgi, F.: Implementation and testing of a desert dust module in a regional climate model, Atmos. Chem. Phys., 6, 4687-4704, doi:10.5194/acp-6-4687-2006, 2006.

Zhang, J. and Reid, J. S.: MODIS Aerosol product analysis for data assimilation: assessment of level 2 aerosol optical thickness retrievals, J. Geophys. Res., 111, D22207, doi:10.1029/2005JD006898, 2006.

Zhang, L., Gong, S., Padro, J., and Barrie, L.: A size-segregated particle dry deposition scheme for an atmospheric aerosol module, Atmos. Environ., 35, 549-560, 2001. 